\title{
Current trends of Chinese herbal medicines on meat quality of pigs. A review
}

\author{
Y. Cui ${ }^{1}$, H. Lu' ${ }^{1}$, Z. Tian ${ }^{1}$, D. Deng ${ }^{1}$ and X. Ma ${ }^{1,2,3}$ \\ ${ }^{1}$ Institute of Animal Science, Guangdong Academy of Agricultural Sciences, State Key Laboratory of Livestock and Poultry \\ Breeding, The Key Laboratory of Animal Nutrition and Feed Science in South China, Ministry of Agriculture, Guangdong \\ Provincial Key Laboratory of Animal Breeding and Nutrition, Guangdong Engineering Technology Research Center of Animal \\ Meat Quality and Safety Control and Evaluation, 510640 Guangzhou, China \\ ${ }^{2}$ Maoming Branch, Guangdong Laboratory for Lingnan Modern Agriculture, 525000 Maoming, China
}

KEY WORDS: Chinese herbal medicine, meat quality, nutritional value, pigs

Received: 15 March 2021

Revised: 12 May 2021

Accepted: 8 June 2021

${ }^{3}$ Corresponding author:

e-mail: maxianyong@gdaas.cn

\begin{abstract}
Chinese herbal medicines (CHMs) contain multiple active ingredients, such as polyphenols, flavonoids, polysaccharides, due to which CHMs have many biological properties for example antioxidant, anti-inflammatory and anti-lipase. CHMs can promote intramuscular fat deposition, increase the content of fatty acids and free amino acids in pork, which increases the nutritional value and health-promoting properties of meat. However, there are still some problems with the application of CHMs in pig production to improve meat quality. Firstly, there are many active ingredients, and their identification and study on their interactions are necessary. Secondly, the presence of harmful ingredients limits $\mathrm{CHMs}$ popularization and application. This review summarizes the current applications of $\mathrm{CHMs}$ in pig production in order to increase meat quality, and compares their effects on meat quality, which provides a theoretical screen for effective CHMs and their combinations. In brief, it is necessary to distinguish and find $\mathrm{CHMs}$ that have positive effects on meat quality and growth performance.
\end{abstract}

\section{Introduction}

In recent years, with the improvement of living standards, consumers are paying more and more attention to pork quality, as high-quality meat that is rich in a variety of nutrients and provides many benefits to human health. The production of natural, safe and healthy animal food products is currently the focus of animal food production worldwide. Research on Chinese herbal feed additives that can not only maintain a certain growth rate but also improve meat quality and flavour, is of great significance to the animal feed industry and human health.

Chinese herbal medicines (CHMs) mainly come from plant roots, stems, leaves and fruits, which are subjected to various processing methods. They have biological activities useful for pharmacological applications in the prevention and treatment of diseases. CHMs contain feed nutrients, such as fat, amino acids (AA), crude protein (CP) and trace elements, which can be used to supplement nutrientdeficient diets. Feeding animals with CHMs with high nutrient contents can not only balance or improve the nutrient level of the diet but also increase the utilization of CHMs. Furthermore, CHMs are rich in a variety of biologically active substances, such as polyphenols, flavonoids, polysaccharides, etc. (Table 1). CHMs also have physiological functions, e.g., antioxidant, anti-inflammatory, antilipase, hepatoprotective (Table 1), and have been widely used in pharmaceutical, food and health products. Animal experiments show that CHMs 
can promote animal growth, enhance immune function and improve the quality of livestock and poultry products. Pigs fed a diet containing CHMs (Astragalus membranaceus, Codonopsis pilosula and allicin mixture) had higher average daily gain, apparent total tract digestibility of dry matter (DM) and gross energy, immunoglobulin concentrations than pigs fed a control diet (Lan et al., 2017). CHMs supplements improve milk yield, milk fat, protein content and immune function in dairy cows under heat stress conditions (Shan et al., 2018). CHMs have many advantages, including ample availability due to a wide range of sources, safety and reliability, no drug resistance, low toxicity, etc. Thus, they are environmentally friendly and can be potential antibiotic substitutes. If we make full use of the by-products of CHMs (residues of CHMs, not recommended for medical purposes, etc.) for animal production, we can recycle more resources and better protect the environment.

Active compounds of CHMs can participate in the regulation of the metabolism of substances in vivo, thereby promoting intramuscular fat (IMF) deposition (Yang et al., 2015), enhancing meat flavour compounds (Ahmed et al., 2016), reducing muscle cholesterol (Kim et al., 2014). Even some beneficial nutrients are derived and accumulated in meat, which can increase the health-added value and meat quality of pork. However, the information about the application of CHMs to enhance the quality of pork is rather rare. In the present review, the effects of CHMs on pork quality from the perspective of pork nutritional value, health benefits, flavour and meat quality are described. The goal is to provide the scientific basis and directions for further research on CHMs impact on meat quality.

Chinese database of China National Knowledge Infrastructure (CNKI), Wanfang Data Knowledge Service Platform and Veipu Information, and the English database of PubMed Central, Science Direct, Scopus, Wiley Online Library, SpringerLink, and the Directory of Open Access Journals were scratched. A tremendous amount of search terms were used to combine terms describing CHMs with words focusing on meat quality between 1999 and 2021. Both general and specific search terms were used, for instance, 'Chinese herbal medicines,' 'herb,' 'plant extract,' 'meat quality,' 'sensory quality,' 'oxidative stability,' and 'pig.' In addition, more specific search terms for the various CHMs were used, such as 'Astragalus membranaceus,' 'Eucommia ulmoides,' and 'mulberry' among others. We used as many relevant search terms as possible for literature search and used publications titles and keywords to remove all articles that did not specifically study the impact of dietary supplementation of CHMs on meat quality of pigs. Then the articles were further screened according to abstracts and methods, including only the research on $\mathrm{CHMs}$ or extracts derived from CHMs. Only herbs identified as CHMs by the Chinese Pharmacopoeia and National Administration of Traditional Chinese Medicine were taken into account.

\section{Types and characteristics of common CHMs used in pig production}

The frequently used CHMs are listed in Table 1. The most frequently used CHMs are Radix Astragali, Fructus Crataegi, Radix Codonopsis, Radix et Rhizoma Glycyrrhizae, Pericarpium Citri Reticulatae, Fructus Hordei Germinatus, Cortex Eucommiae, Caulis Lonicerae Japonicae, Folium Mori, Radix Angelicae Sinensis, Massa Medicata Fermentata and Rhizoma Atractylodis Macrocephalae. Additionally, since these herbs are rich in biologically active compounds, they are used in Western medicine for their antioxidant, antiinflammatory, antiviral and antibacterial activities (Table 1). Therefore, the addition of these herbs to animal feed has certain benefits for the antioxidant system of pigs, which can enhance immunity and disease resistance and thus promote health. At the same time, some functional compounds may be deposited in pork, which bestows the pork with better oxidative stability and thereby potentially extends its shelf-life.

\section{Problems in the application of CHMs}

\section{The number of active ingredients is difficult to identify}

Due to numerous active ingredients present in CHMs, it is difficult to determine all of them. The content of these active compounds in CHMs/extracts varies greatly, depending on the herbal part (seeds, leaves, stems, roots) from which it was prepared, geographical origin, maturation stage, preservation method and period, storage and extraction method. Moreover, the interaction of bioactive components in herbal formulas is not only confined to absorption, metabolism and enzymatic reaction, but also to processing, single and multiple formulas (Wang et al., 2012b). In the processing, especially under 


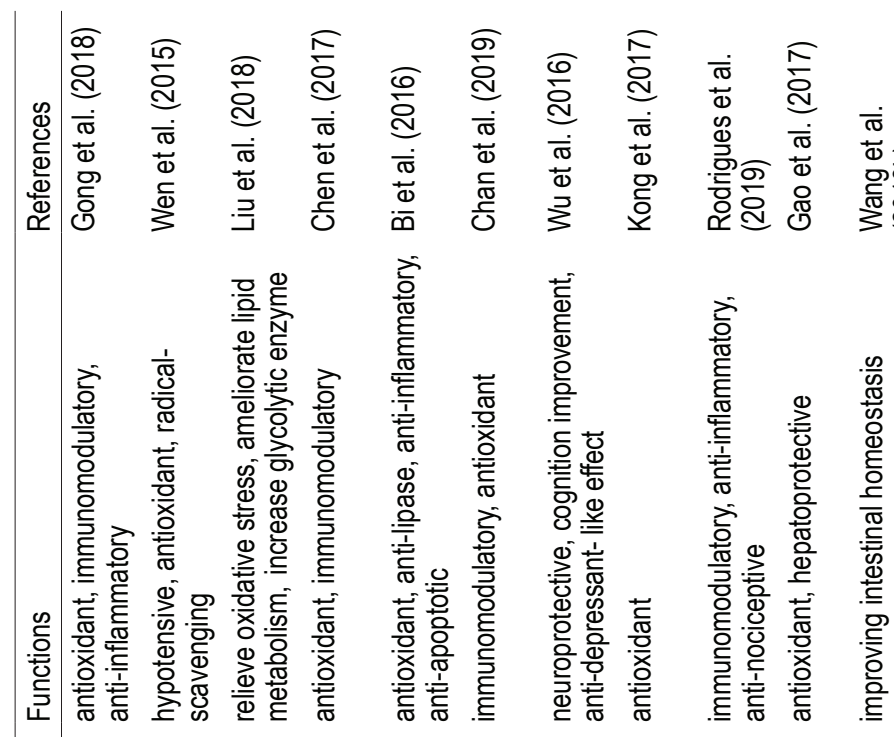

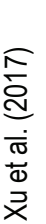

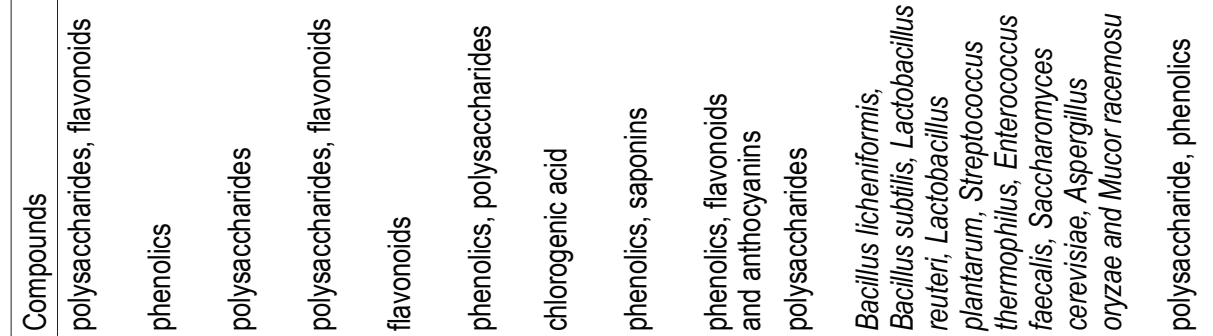

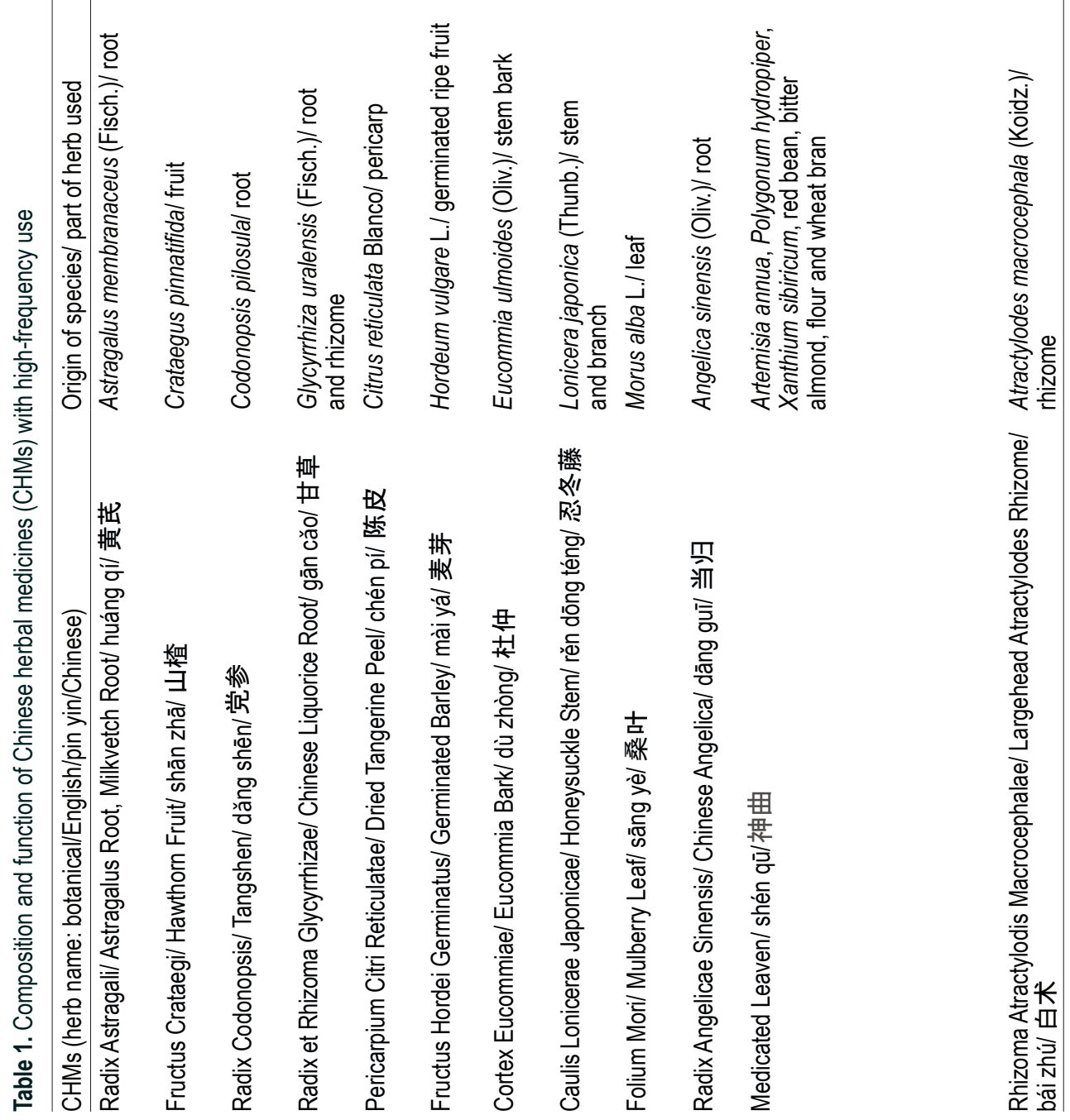


heating and/or wet conditions, the composition of CHMs may undergo complex changes, such as content increase or decrease, structural changes, and/or formation of new compounds (Wu et al., 2018). Furthermore, CHMs consists of a variety of herbal ingredients and hundreds of compounds, so their therapeutic effect depends on the overall interaction between all ingredients. In a word, each kind of CHMs has different effects.

\section{Harmful ingredients limit their popularization and applsication}

Common contamination of CHMs products include microorganisms, toxins, insecticides and/ or toxic heavy metals. Liver and kidney injury caused by other CHMs in recent years has been reported. These include Polygonum multiflorum, Aloe barbadensis, Atractylis gummifera, Symphytum officinale, Nerium indicum, Xanthium strumarium, Tripterygium wilfordii, Aconitum carmichaelii (Lin et al., 2017; Liu et al., 2019b; Zong et al., 2019; Song et al., 2020). In particular, CHMs rich in polysaccharides and starches were found to be susceptible to harmful fungi. It has been found that certain CHMs, such as Angelica sinensis, citrus and licorice, are contaminated with aflatoxin (Hu et al., 2018b). In a study by Ting et al. (2013), Bacillus was the most common recycling pollutant when compared with Clostridium and Staphylococcus. Residues of 16 pesticides were identified in $72.1 \%$ of the 104 herbal samples (Kowalska, 2020). If CHMs powder was used directly in the aquaculture industry (or CHMs that do not meet the standard for the use in humans), it may endanger pigs health, and toxins may even accumulate in pork products. Moreover, pork products can also be contaminated if improperly preserved CHMs residues from herbal medicine factories are used as pig feed.

Another important issue is that the toxic compound content of wild-collected plants is higher than that of cultivated ones (Harris et al., 2011). Also, it was found that the average dissolution rates of zinc, copper, cadmium, mercury, arsenic and lead in four kinds of CHMs were 47.4, 33.8, 20.5, 6.1, 5.4 and $4.8 \%$, respectively, and the CHMs were considered to pose no threat to human health (Wang et al., 2019). Nan et al. (2021) reported that the Platycodon grandiflorum accumulated varying amounts of metal(loid)s in the order copper $>$ mercury $>$ lead $>$ arsenic $>$ cadmium, and their concentrations decreased in the early growth stage and then increased in the flowering season. However, unlike human drinkable decoction, heavy metals may accumulate in tissues of pigs fed diets directly supplemented with herbal powder, especially when the dosage is large.

Therefore, to promote the use of CHMs in actual production we need to address certain issues beforehand. Firstly, the effect of CHMs and their collocation effect must be fully understood. Secondly, the presence of harmful substances in CHMs must be detected in order to avoid the use of CHMs with high content of harmful materials.

\section{Effect of CHMs on pork nutritional value}

\section{Conventional nutritional composition}

Numerous CHMs have both medicinal properties and nutritional value in practical use. For example, Folium Mori is rich in $\mathrm{CP}$, fat and vitamins (Chen et al., 2021), and Radix Astragali is rich in polysaccharides, AA, CP and mineral (Lan et al., 2017). Feeding animals with CHMs can transform nutrients in CHMs into nutrients in animals, which is helpful to enhance the nutritional value of pork. As reported by Lin et al. (2020), CHMs compounds (e.g., Semen Raphani, Atractylodes, Semen Coicis, Poria, Crataegus, Codonopsis pilosula, Sophora japonica, Pulsatilla chinensis, Portulacae, Semen Euryales, Radix Scutellariae, Copperleaf herb, Astragalus, Rhizoma coptidis, Pseudollaria heterophylla, dried orange peel - in various mixtures) improved the contents of $\mathrm{CP}$, total AA, total lipid, ash, calcium and phosphorus in pork.

\section{Water/ dry matter}

Many researchers have confirmed that some CHMs (Folium Mori (mulberry leaves), Radix Sophorae, Radix Glycyrrhizae, Radix Astragali, Cortex Eucommiae as well as Origanum vulgare (oregano) essential oil) do not affect pork water content or DM (Kim et al., 2014; Cheng et al., 2017; Yu et al., 2017; Chen et al., 2021). However, Kang et al. (2012) reported that the pork water content was significantly higher in pigs treated with CHMs byproducts (Cynonchum witfordii, Curcuma zedoaria, Pueraria thumbergiana) than those treated with flavomycin. On the other hand, CHMs increased the pork water content and decreased the fat content, which may affect the flavour of pork. Ahmed et al. (2016) reported that natural and fermented herbs (Punica granatum, Ginkgo biloba, Glycyrrhiza uralensis) significantly increased the water content and decreased the crude fat in the longissimus dorsi 
muscle (LDM) of pigs. Xiangcun Black pigs fed diet containing $6 \%$ mulberry leaves have a lower content of DM in LDM in comparison with the control group (Liu et al., 2019a).

\section{Ash}

It has been reported that CHMs do not affect the ash content of pork, neither a single CHM (oregano; Cheng et al., 2017) nor a compound formula (Punica granatum, Ginkgo biloba, Glycyrrhiza uralensis (Ahmed et al., 2016); Astragalus membranaceus, Glycyrrhiza uralensis, Angelica dahurica (Yang et al., 2015)). However, other studies have reported that CHMs can improve the ash content of pork. Kang et al. (2012) found that the ash content in pork treated with the CHMs by-products (Cynonchum witfordii; Curcuma zedoaria, Pueraria thumbergiana) was significantly higher than that in pork treated with $0.1 \%$ flavomycin. Similarly, the ash content in pork from pigs fed diets with Eucommia ulmoides leaves was significantly higher than that in pigs fed basal diet (Lee et al., 2009). The phosphorus content in pigs fed CHMs (Sophora japonica, Pulsatilla chinensis, Portulacae) increased significantly (Lin et al., 2020).

Ash mainly includes inorganic salts and oxides. There are two main points in the mechanism of CHMs to improve muscle ash content. 1) Possibly, CHMs may have a high minerals content, thereby promote the deposition of minerals in the muscles. Some edible herbs have high mineral content and are harmless, so they can be used as dietary supplements (Ozyigit et al., 2018). Medicinal plants contain many important essential and beneficial elements involved in various metabolic processes. However, the toxicity of these elements may cause serious health problems. Therefore, it is necessary to determine the minerals nutritional value and accumulation state of heavy metals in CHMs. 2) CHMs may stimulate mineral absorption. For instance, natural and fermented herbs increased the content of calcium and iron (Ahmed et al., 2016). Moreover, treatment with the ethanol extract of Fructus Ligustri Lucidi can regulate bone turnover and upregulate the expression of calcium absorption-related genes in kidney and duodenum, and increase the calcium absorption and retention efficiency (Feng et al., 2014). Thus, the increase of mineral content through dietary supplementation in pork may to some extent contribute to human health.

\section{Crude fat/ intramuscular fat}

It was suggested that certain CHMs have no effect on meat crude fat content, such as Eucommia ulmoides leaves (Lee et al., 2009), oleuropein extract (Lin et al., 2020) and CHMs formulas (CHMs byproducts including Cynonchum witfordii, Curcuma zedoaria, Pueraria thumbergiana; and compounds including Astragalus membranaceus, Glycyrrhiza uralensis, Eucommia ulmoides) (Kang et al., 2012; Zeng, 2016).

However, it has been suggested that CHMs (Massa Medicata Fermentata, Fructus Aurantii, Angelica sinensis and Astragalus membranaceus, Glycyrrhiza uralensis, Angelica dahurica) can regulate the deposition of IMF in pork by increasing the pork fat content, increasing the marbling score and promoting flavour (Wang et al., 2013; Yang et al., 2015). For instance, in some studies, it was revealed that tea residue and oregano essential oil $(250 \mathrm{mg} / \mathrm{kg}$ ) can increase IMF (Tong, 2016; Cheng et al., 2017). The added amount of different CHMs may have an impact on fat production. Mulberry leaves (3-12\%) had no effect on the IMF content in pigs (Liu et al., 2019a; Chen et al., 2021), while 15\% mulberry leaves significantly increased the IMF content (Zeng et al., 2019). Significantly increased IMF was observed in the $80 \mathrm{mg} / \mathrm{kg}$ cinnamaldehyde group and no increase of IMF was noted in $40 \mathrm{mg} / \mathrm{kg}$ supplemented group in comparison with the control group (Luo et al., 2020). Bioactive compounds of CHMs regulate fat deposition and metabolism, such as, mulberry anthocyanins can reduce lipogenesis and promote hepatic lipid clearance (Chang et al., 2013); 1-deoxynojirimycin promoted the plasma adiponectin and activated the $\beta$-oxidation system to reduce the weight of visceral fat and the size of adipocyte (Tsuduki et al., 2013). Chlorogenic acid from Eucommia ulmoides leaves improves lipid metabolism by transcriptional activation of adenosine 5'-monophosphate-activated protein kinase and inhibition of its downstream targets, to inhibit total cholesterol synthesis, total cholesterol and triacylglycerol levels in hepatocytes (Hao et al., 2016).

In addition, feeding pigs diets containing two formulas (1: Caulis Lonicerae Japonicae, Radix Astragali, Polygoni Multiflori Radix, Massa Medicata Fermentata, Pine needles, Radix Angelicae Sinensis; 2: Pericarpium Citri Reticulatae, Fructus Hordei Germinatus, Fructus Crataegi, Radix Codonopsis, Atractylodes Lancea, Scutellaria baicalensis Georgi, Cyrtomium fortunei) of CHMs significantly increased the crude fat content of LDM, including Lonicera japonica, Astragalus membranaceus, Fallopia multiflora and dried tangerine peel, malt, and Crataegus pinnatifida (Xu et al., 2012). The cure fat content in pigs fed three mixtures of CHMs 
(A: Semen Raphani, Atractylodes, Semen Coicis, Poria, Crataegus, Codonopsis pilosula; B: Sophora japonica, Pulsatilla chinensis, Portulacae, Atractylodes, Semen Euryales, Radix Scutellariae; C: Copperleaf herb, Astragalus, Atractylodes, Rhizoma coptidis, Pseudollaria heterophylla, dried orange peel) was $12.84-17.57 \%$ higher than in control pigs (Lin et al., 2020). The supplementation of CHMs (Astragalus membranaceus, Eucommia ulmoides, Ginkgo biloba) increased by $9.12 \%$ crude fat of LDM in comparison with the zero supplementation (Shen et al., 2021). Similarly, the CHMs formula (Radix Astragali, Radix Glycyrrhizae, Cortex Eucommiae) used in the research of Yu et al. (2017) had the same effect. According to the above research, it can be concluded that CHMs increasing fat content mainly include Astragalus membranaceus, Fructus Crataegi, Fructus Hordei Germinatus, Glycyrrhiza uralensis, Pericarpium Citri Reticulatae and some contain Angelica sinensis, Lonicera japonica and Codonopsis pilosula. Madak-Erdogan et al. (2016) reported that Radix Glycyrrhizae reduced weight gain and total fat deposition after ovariectomy. Furthermore, Astragalus membranaceus polysaccharides can reduce the increase of body weight and liver triglyceride induced by metabolic stress (Huang et al., 2017). Ethanol extract of Crataegus pinnatifida fruit had a good hypolipidemic effect (Shao et al., 2016). Pericarpium Citri Reticulatae decreased liver lipid content and improved lipid metabolism in ovariectomized rats (Lim et al., 2014). In addition, the combination of Citrus unshiu and Crataegus pinnatifida leaves inhibited lipogenesis (Lee et al., 2015). Honeysuckle anthocyanins at 100 or $200 \mathrm{mg} / \mathrm{kg}$ dose can inhibit body weight gain, reduce serum and liver lipid profiles, ameliorate liver dysfunction, and their anti-obesity effects might be through the blockage of lipid accumulation (Wu et al., 2013). Therefore, it is established that many CHMs have fat-reducing activity. Remarkably, it seems that the CHMs with fat-reducing activity cannot achieve the effect of increasing meat fat content. The most likely explanation is that active ingredients of compound CHMs that improve crude fat content do not come from a single CHM. The most important factors for improving the IMF content are the interaction and synergy of the herbal ingredients, while the proportion, dosage and composition of CHMs greatly affect the fat deposition.

Generally, IMF is derived from the liver (mainly dietary lipids) and adipose tissue (mainly neonatal lipogenesis) (Corominas et al., 2013). At the same time, there are only some studies on CHMs impact on muscle fat deposition, and the deposition of muscle is mainly discussed as the result of liver fat metabolism. However, the deposition of IMF is inconsistent with the deposition of body fat. IMF is a specific metabolic characteristic controlled by specific genes expression pathways (Hocquette et al., 2010). The relative effects of direct deposition in dietary fat and endogenous synthesis, as well as the regulation of dietary ingredients composition, are key factors in porcine lipid metabolism. The underlying mechanisms of these complex physiological processes have not yet been well understood. Therefore, oils and fats in CHMs, especially fatty acids (FA), may have an effect on lipid metabolism and muscle fat. A diet rich in unsaturated fatty acids (UFA) leads to lower fat deposition and IMF content (Isabel et al., 2014). Studies on fat deposition in pigs are mainly focused on fat production, but less on fat decomposition. Although at present, the mechanism of CHMs mediating the improvement of IMF deposition is not clear. CHMs can improve the distribution and deposition of pork fat, reducing the visceral and body fat content, which helps to satisfy people's contradictory requirements for taste and obesity.

\section{Protein}

Some studies have indicated that CHMs such as natural herbs (Punica granatum, Ginkgo biloba, Glycyrrhiza uralensis; Radix Astragali, Radix Glycyrrhizae, Cortex Eucommiae), have no effect on the muscle CP content (Ahmed et al., 2016; Yu et al., 2017). CHMs can regulate muscle protein deposition, increase or decrease the $\mathrm{CP}$ content. It is well known that many CHMs are both medicinal and edible. The AA composition of CHMs is similar to that of the botanical feed, that is, the AA composition in plant protein precursors is not the only factor that affects protein content (Kong et al., 2011). Eucommia ulmoides (Lee et al., 2009) and Morus alba leaves (Liu et al., 2019a) can increase the CP content of LDM. The $\mathrm{CP}$ and total AA of pigs fed diets with CHMs mixture (Semen Raphani, Atractylodes, Semen Coicis, Poria, Crataegus, Codonopsis pilosula) increased by 4.54 and $5.67 \%$, respectively, in comparison with the control animals (Lin et al., 2020).

However, some CHMs reduced muscle CP content, e.g., oregano essential oil (Cheng et al., 2017) and Cynonchum witfordii, Curcuma zedoaria, Pueraria thumbergiana (Kang et al., 2012). Kong et al. (2011) suggested that some CHMs compounds have similar structures and physiological functions to glucocorticoids. Thus, such compounds may improve the metabolism of nutrients and protein deposition 
through cell signalling pathways. On the one hand, it can be speculated that $\mathrm{CHMs}$ have a characteristic odour and poor palatability as medicines. A high dose of CHMs may reduce the feed intake in pigs, resulting in insufficient energy and protein synthesis. In summary, in animal feeding, the use of CHMs mostly plays a role in nutritional prevention. The correct doses between nutritional and pharmacological prevention is crucial for muscle $\mathrm{CP}$ deposition and animal healthy growth.

\section{Cholesterol}

CHMs can regulate pork lipid metabolism. In many studies, it has been reported that CHMs (Folium Mori, Radix Sophorae, Radix Glycyrrhizae; coptis extract; Silybum marianum (milk thistle)) reduce the cholesterol content of pork and atherosclerosis index (Kim et al., 2014; Grela et al., 2020; Yi and Liu, 2020). In other studies, it was found that herbs can inhibit liver fat production and cholesterol enzyme activity (Warshafsky et al., 1993). Ahmed et al. (2016) found that pigs fed diets with natural herbals (Punica granatum, Ginkgo biloba, Glycyrrhiza uralensis) had significantly decreased cholesterol content in longissimus thoracis et lumborum (LTL) muscle. Plant flavonoids and cholesterol of digesta can form insoluble compounds, which inhibits the absorption of endogenous and exogenous cholesterol in the intestine and increase faecal cholesterol and bile acid excretion (Wang et al., 2012a). CHMs with high fibre content may reduce muscle cholesterol levels (Kang et al., 2012). Certainly, a lower cholesterol level in pork can reduce the incidence of cardiovascular diseases, which is beneficial to human health.

\section{Flavour substances}

Fatty acids. FA can react with the Maillard reaction compounds to form flavour compounds with a lower odour threshold and therefore a potentially greater impact on the flavour (Aaslyng and Meinert, 2017). CHMs not only can improve the distribution of FA in meat but also the nutritional value, thereby promoting human health. The reduction of saturated fatty acids (SFA) and the relative increase of UFA are beneficial for humans. As shown in the Table 2, some CHMs can increase the content of oleic acid, linoleic acid, linolenic acid and UFA, but others may reduce their content. The same is true for SFA. The CHMs promoting the improvement of muscle fat may have positive effects on oleic and linoleic acid. Oregano essential oil may cause a redistribution of oleic and linoleic acid in the IMF (Cheng et al., 2017). Additionally, the main factor influencing the con- centration of oleic and linoleic acid in adipose tissue is the total amount of fat itself (Wood et al., 2013). Therefore, the CHMs promoting the improvement of muscle fat may have positive effects on oleic and linoleic acid.

However, many studies have suggested that CHMs can reduce fat (section of crude fat/ IMF), and it is difficult to determine the extent to which CHMs have direct or indirect effects on FA composition. Mainly, this is due to the complexity and diversity of CHMs. Each herb is rich in bioactive metabolites, as a result, their mechanism of action on muscle FA is more complicated. It is generally recognized that the FA composition of tissues also depends on endogenous synthesis, which may also be affected by dietary composition. As shown in a study by Ahmed et al. (2016), a high concentration of $\alpha$-linolenic acid in fermented herbs (Punica granatum, Ginkgo biloba, Glycyrrhiza uralensis) reduces FA concentration and arachidonic acid synthesis in meat, which can compete with linoleic acid for the same enzymes (Waszkiewicz-Robak et al., 2015). Furthermore, it is also widely known that changes in dietary fat have various effects on the expression of genes involved in lipid metabolism. Coptis extract can change the gene expression of fat and muscle metabolism in vivo, and reduce the total SFA concentration of LDM (Yi and Liu, 2020). Moreover, lipids are particularly susceptible to oxidation. For instance, it has been reported that plant polyphenol dietary supplements can effectively change the composition of FA by preventing the oxidation of UFA (Rincón-Cervera et al., 2016). In order to confirm the effect of CHMs on the FA composition of meat, further research is needed. Researchers can also consider using CHMs to regulate fat metabolism and change the metabolism and distribution of FA in pork, which is beneficial to human health.

Free amino acids and inosine monophosphate. Free amino acids (FAA) in pork are tasty and so affect the flavour of meat. FAA can react with reducing sugars to form Maillard reaction products and promote meat flavour (Aaslyng and Meinert, 2017). Muscle aminopeptidase contributes to the production of FAA after death, thereby improving meat nutritional value and affecting its flavour by acting as flavour enhancers or precursors of aroma compounds (Toldrá et al., 1995). Rincón-Cervera et al. (2016) and Long (2015) suggested that Lonicera macranthoides, Astragalus membranaceus, Eucommia ulmoides, Ginkgo biloba increased the content of FAA (arginine, glutamate, serine, tyrosin, isoleucine, threonine, valine; glycine, arginine, 


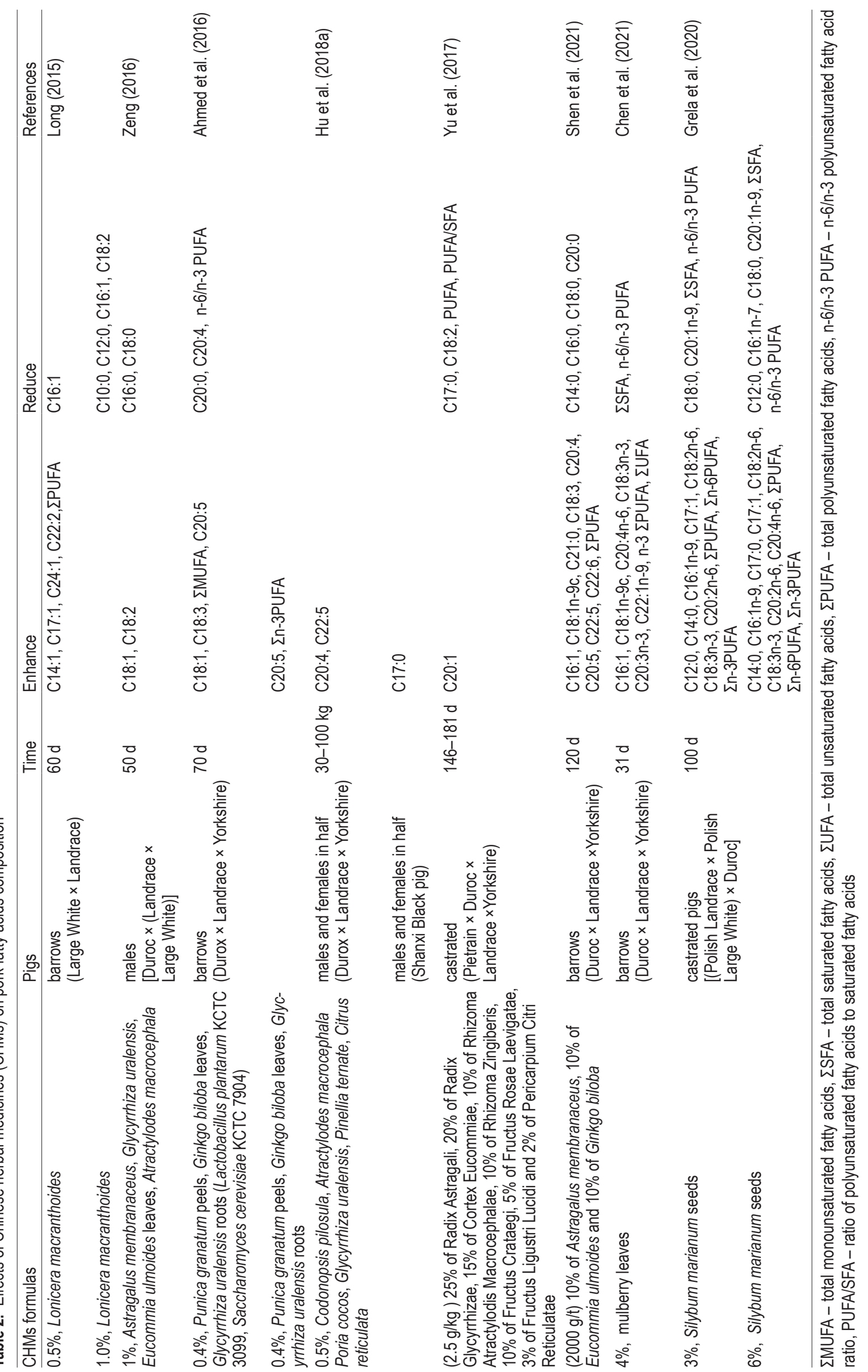


phenylalanine, valine, leucine and lysine) in pork. Mulberry leaves (4\%) supplementation increased the contents of glutamic acid, glycine, alanine, arginine, isoleucine, phenylalanine, proline, serine, tyrosine, aspartic acid and total AA (He et al., 2019; Chen et al., 2021), but 6\% mulberry leaves addition decreased the concentration of lysine and glutamine (Liu et al., 2019a). In Lin et al. (2020) study, a CHMs mixture A: Semen Raphani, Atractylodes, Semen Coicis, Poria, Crataegus, Codonopsis pilosula) increased the concentrations of valine, phenylalanine, aspartic acid, glutamic acid, glycine, alanine, arginine, and leucine in LDM, and the concentrations of methionine, leucine and proline were increased by two others CHMs mixtures (B: Sophora japonica, Pulsatilla chinensis, Portulacae, Atractylodes, Semen Euryales, Radix Scutellariae; C: Copperleaf herb, Astragalus, Atractylodes, Rhizoma coptidis, Pseudollaria heterophylla, dried orange peel).

It is suggested that growth-promoting effects of CHMs lead to rapid deposition of muscle protein, turnover of body proteins, increase activity of myofibril degrading enzymes, resulting in an increase in the FAA content in water-soluble substances in meat (Shuang et al., 2001). Diets containing 1 or $1.5 \%$ honeysuckle leaf powder increased the concentration of several FAA and the mRNA expression of the selected AA transporters in the longissimus muscles of Chinese Tibetan pigs, significantly increasing the mRNA expression of genes related to muscle growth (Wang et al., 2017). However, CHMs probably affect the metabolism of nutrients (especially AA) in the small intestine by altering the growth and metabolism of intestinal microbiota, thereby changing the amount of AA (free or protein bound) (Kong et al., 2011).

Liu et al. (2019) found that 3-12\% of mulberry leaves increased inosine monophosphate (IMP) content, but Chen et al. (2021) reported that $4 \%$ of mulberry leaves did not increase IMP content. However, there are few studies focused on the effects of CHMs on FAA and IMP, as a result, we currently do not understand the mechanisms whereby CHMs can improve the content of FAA or IMP.

\section{Meat quality}

\section{Marbling score}

Marbling is the texture formed by the distribution of fat and connective tissue in the muscle, which is closely related to the flavour, tenderness and juiciness of meat (Chen et al., 2015). In some studies, it was implied that CHMs (Eucommia ulmoides leaves, Scutellaria baicalensis and Lonicera japonica extract, coptis extract) have no effect on marbling score (Lee et al., 2009; Liu et al., 2016; Yi and Liu, 2020). On the other hand, several studies have shown that tea residue (Tong, 2016), garlic (Yan et al., 2011), compound CHMs (Lonicera japonica, Astragalus membranaceus, Polygonum multiflorum) (Xu et al., 2012) and $80 \mathrm{mg} / \mathrm{kg}$ cinnamaldehyde (Luo et al., 2020) can improve the pork marbling score. Additionally, Wang etal. (2018a) reported that CHMs (Astragalus membranaceus, Acanthopanax senticosus, Codonopsis pilosula) increased the marbling score by $30.41 \%$ in comparison with the control. The diet supplemented with Astragalus membranaceus, Eucommia ulmoides and Ginkgo biloba increased the marbling score of pork by $56 \%$ (Shen et al., 2021). The marbling scores for the CHMs formula (Radix Astragali, Radix Glycyrrhizae, Cortex Eucommiae) at a dose of $2.5 \mathrm{~g} / \mathrm{kg}$ in the dietary treatment were increased, but for the dietary treatment at a dose of $5 \mathrm{~g} / \mathrm{kg}$ the marbling scores were similar to those of the control (Yu et al., 2017). In order to increase people's desire to purchase the product, for production, it is necessary to screen for herbs with an improved marbling score effect.

\section{pH value}

Undoubtedly, the influence of the rate and extent of the decrease of the $\mathrm{pH}$ value on protein denaturation, the myofibrillar lattice spacing and shrinkage in muscle cells is fundamental in determining the quality of raw and cooked meat (Hughes et al., 2014). In general, the final $\mathrm{pH}$ value of most of the pork with normal glycolysis is from 5.3 to 5.8 (Warriss, 1982). Several studies have reported that CHMs can improve pork $\mathrm{pH}$ at $24 \mathrm{~h}$, such as the combination of Portulaca oleracea and Fructus Crataegi, tea residues (Tong, 2016); compounds (Gastrodia elata, licorice) (Kang et al., 2012), coptis extract (Yi and Liu, 2020), Eucommia ulmoides (Li et al., 2020; Zhang et al., 2020), milk thistle seeds (Grela et al., 2020), mulberry leaves (Fan et al., 2020; Zeng et al., 2019), cinnamon extract (Luo et al., 2020). Higher $\mathrm{pH}$ value at $24 \mathrm{~h}$ after slaughter could be due to the inhibition of lipolysis by antioxidant supplements and lower FA release (Wood et al., 2004). It may also be due to the active ingredients of CHMs. Quercetin in mulberry leaves can inhibit muscle glycolysis by down-regulating glycolysis-related enzymes (Dihal et al., 2008). Cinnamaldehyde can reduce the activities of phosphoglycerate kinase 
(PGK) and glyceraldehyde 3-phosphate dehydrogenase (GAPDH), and improve $\mathrm{pH}$ value (Luo et al., 2020). Dietary supplementation of Eucommia ulmoides extract can increase sarcoplasmic reticulum $\mathrm{Ca}^{2+}$-ATPase (SERCA) activity and $\mathrm{pH}$ value (Li et al., 2020). Certainly, Glycyrrhiza uralensis, Portulaca oleracea and theophylline have powerful sedative and hypnotic effects (Xu et al., 2007; Singh and Zhao, 2017; Hamedi et al., 2019). Accordingly, it can be inferred that those CHMs can reduce stress by reducing glycolysis, which eventually leads to increase muscle final $\mathrm{pH}$, to some extent.

There are conflicting reports about the effect of garlic powder on the muscle $\mathrm{pH}$ value at $24 \mathrm{~h}$. For instance, some studies have suggested that the average $\mathrm{pH}$ value at $24 \mathrm{~h}$ is higher in the group with added garlic than that in the group with no added garlic (Holden et al., 1999; Chen et al., 2008). In contrast, Yan et al. (2011) reported that fermented garlic powder had no effect on the $\mathrm{pH}$ value at $24 \mathrm{~h}$. This is mainly due to the difference between the nutritional density of the diets, and the functional substances of garlic that have undergone fermentation.

\section{Tenderness/ shear force}

Tenderness refers to the perception of the meat chewing process. It is mainly determined by the content and chemical structure of myofibrils, connective tissue and sarcoplasmic protein in muscle (Listrat et al., 2016). Some studies have suggested that CHMs (Folium Mori, Radix Sophorae, Radix Glycyrrhizae, Verbena officinalis extract; oregano essential oil) have no effect on pork tenderness (Kim et al., 2014; Rossi et al., 2014; Forte et al., 2017). In contrast, other studies have reported that some CHMs (Lonicera japonica, Astragalus membranaceus, Polygonum multiflorum, Glycyrrhiza uralensis, Angelica dahurica) can reduce the shear force (Xu et al., 2012; Yang et al., 2015) and improve the tenderness of pork. The shear force was significantly reduced by $18.38 \%$ in the $0.1 \%$ CHMs group (Cortex dictamni, Ligusticum wallichii, prepared Rehmannia Glutinosa) in comparison with the control (Li et al., 2014). Astragalus membranaceus, Eucommia ulmoides, Ginkgo biloba and milk thistle seeds increase tenderness by reducing shear force or shear energy (Grela et al., 2020; Shen et al., 2021). The tenderness of meat is closely related to the diameter of the muscle fibres and IMF. Indeed, Wang et al. (2018a) reported that $1 \%$ of compound CHMs (Astragalus membranaceus, Acanthopanax senticosus, Codonopsis pilosula) have tendency to reduce the muscle fibre diameter. In another study, supplementation with a polyphenolic extract from
Eucommia ulmoides leaves increased the fibre density but decreased fibre diameter in comparison with the control group (Zhou et al., 2016). In contrast to type IIb fibres, type I fibres have a finer diameter, lower shear and better softness (Hamill et al., 2012). Mulberry leaves powder decreased shear force ( $\mathrm{He}$ et al., 2019; Chen et al., 2021), but $12 \%$ of mulberry leaves increased shear force (Chen et al., 2021). Mulberry leaves induced higher mRNA levels of genes encoding myosin heavy chain (MyHC) I and IIa (Zeng et al., 2019; Chen et al., 2021), and lower gene expression of genes encoding MyHC IIx and MyHC IIb (Liu et al., 2019a; Chen et al., 2021). This may be due to the active substances in mulberry leaves. Resveratrol is abundant in mulberry leaves ( $\mathrm{He}$ and $\mathrm{Lu}, 2013$ ), which could increase MyHC IIa mRNA level and decreased MyHC IIb mRNA level (Zhang et al., 2015; Cheng et al., 2020). These findings indicated that reasonable amounts of CHMs can improve pork tenderness.

\section{Water holding capacity}

Water holding capacity (WHC) is defined as the ability of fresh meat to retain its own water during cutting, heating, grinding and pressing and during transport, storage and cooking (Hughes et al., 2014). Long (2015) found that Lonicera macranthoides (extract) did not influence cooking loss. It was reported that CHMs improve the WHC in pork. In one study, the combined use of Fructus Aurantii, Angelica sinensis, Fructus Crataegi and other herbs reduced the water loss rate (Wang et al., 2013). In Cheng et al. (2020) study, the drip loss in meat of pigs fed diets with CHMs (Semen Raphani, Atractylodes, Semen Coicis, Copperleaf herb, Astragalus) was lower than that of the control group. In other studies in which Lonicera japonica and Fructus Crataegi mixture or Portulaca oleracea and Fructus Crataegi mixture were used, similar findings were reported (Xu et al., 2012; Tong, 2016). The key to the reduction in drip loss is to protect the integrity of the cell membrane (Kang et al., 2012). Together, all these CHMs formulas contain Fructus Crataegi. Presumably, Fructus crataegi can protect cell membrane integrity and reduce muscle serum leakage. Fructus Crataegi extract changes the packaging order of porcine erythrocyte membrane lipid polarity head and induces spines, and improves membrane structure, to protect membrane lipids from oxidation (Włoch et al., 2013).

Besides, the effect of a single herb on the WHC of pork is different. For instance, the diet with the addition of mulberry leaves, Eucommia ulmoides (power/extract), oleuropein extract, Achyranthes 
japonica Nakai extract, cinnamon extract and milk thistle seeds reduced cooking loss or drip loss (Zeng et al., 2019; Dang et al., 2020; Grela et al., 2020; Li et al., 2020; Luo et al., 2020; Chen et al., 2021; Rey et al., 2021). In these studies, dietary CHMs supplementation showed the ability to improve the WHC of meat. This positive effect of CHMs may be attributed to the increase of $24 \mathrm{~h} \mathrm{pH}$ and/or the prevention of lipid and protein oxidative damage. Moreover, other studies have reported that after adding garlic, the WHC was higher (Holden et al., 1999; Chen et al., 2008), while fermented garlic powder had no effect on drip loss (Yan et al., 2011). These effects may be related to changes in garlic before and after fermentation.

\section{Meat colour}

Meat colour is an important factor for consumers, giving preference to pork with high red intensity (Faustman et al., 2010). Improving pork colour may satisfy the consumers' expectations for meat. To date, some researchers have suggested that CHMs (Scutellaria baicalensis and Lonicera japonica extract, cinnamon extract) have no positive effect on the pork colour score (Liu et al., 2016; Luo et al., 2020). However, the following studies describe the effects of CHMs on different meat colour indicators. Garlic $(1 \mathrm{~g} / \mathrm{kg})$ treatment resulted in meat that had higher colour, marbling and firmness score than the control treatment, whereas lightness $\left(\mathrm{L}^{*}\right)$, yellowness $\left(\mathrm{b}^{*}\right)$ and redness $\left(\mathrm{a}^{*}\right)$ values were lower than those in other treatments (Chen et al., 2008). Dietary supplementation with CHMs mixture (Astragalus membranaceus, Eucommia ulmoides, Ginkgo biloba) increased the meat colour score of pigs by $57.51 \%$ (Shen et al., 2021). Yu et al. (2017) reported that the colour scores of meat from animals fed diet with addition of $2.5 \mathrm{~g} / \mathrm{kg}$ of CHMs mixture: Radix Astragali, Radix Glycyrrhizae, Cortex Eucommiae Radix Astragali, Radix Glycyrrhizae, Cortex Eucommiae, were improved, while the scores of meat from the animals fed diet supplemented with $5 \mathrm{~g} / \mathrm{kg}$ of this mixture were similar to those of the control group.

Lightness $\left(\mathbf{L}^{*}\right)$. Most studies suggest that CHMs (Scutellaria baicalensis and Lonicera japonica extract; Eucommia ulmoides leaves; Astragalus membranaceus, Glycyrrhiza uralensis, Cinnamomum cassia; Verbenaceae leaves extract; coptis extract) have no effect on pork $L^{*}$ values (Liu et al., 2016; Zhou et al., 2016; Rossi et al., 2017; Wei et al., 2019; Yi and Liu, 2020). However, in some studies, it was reported that CHMs (Astragalus membranaceus, Angelica sinensis, Codonopsis pilosula) have a positive effect on the improvement of the pork L* values (Tian et al., 2009). For instance, the $\mathrm{L}^{*}$ values of pork treated with Lonicera macranthoides (Long, 2015), Astragalus membranaceus, Codonopsis pilosula and allicin mixture (Lan et al., 2017) were significantly reduced.

Redness $\left(\mathbf{a}^{*}\right)$. There is a lot of evidence suggesting that CHMs (Portulaca oleracea and Fructus Crataegi, tea residues; Glycyrrhiza uralensis, Eucommia ulmoides, coptis extract) do not affect meat redness (Tong, 2016; Zeng, 2016; Yi and Liu, 2020). However, some studies have found that CHMs can increase pork redness. Among them are Massa Medicata Fermentata, combination of Astragalus membranaceus, Codonopsis pilosula and allicin mixture, milk thistle seeds, and Verbenaceae leaves extract (Lan et al., 2017; Rossi et al., 2017; Wang et al., 2018b; Grela et al., 2020). Yu et al. (2017) reported that the $\mathrm{a}^{*}$ values at 45 min of meat from animals fed diet with the $2.5 \mathrm{~g} / \mathrm{kg}$ of compound CHMs were improved, while those of animals fed diet with $5 \mathrm{~g} / \mathrm{kg}$ of compound CHMs were similar to the control group. The $\mathrm{a}^{*}$ values of pork from animals fed diets with CHMs (Astragalus membranaceus, Glycyrrhiza uralensis, Cinnamomum cassia) was $10.99 \%$ higher than that of control (Wei et al., 2019).

To date, most studies have focused on the $\mathrm{a}^{*}$ values at $45 \mathrm{~min}$ of slaughter, and few on $24 \mathrm{~h}$. One study suggested that the difference in the $a^{*}$ values at 45 min between CHMs and basal diet was not significant, but the a* values at $24 \mathrm{~h}$ in CHMs increased significantly (Li et al., 2014). Similarly, mulberry leaves improved the $a^{*}$ values of pork at $45 \mathrm{~min}$ and at $24 \mathrm{~h}$ (Zeng et al., 2019).

The composition of muscle fibres affects the meat colour through their effect on the amount and chemical state of myoglobin. The high myoglobin content in type I and type IIA fibres leads to a positive correlation between the proportion of these fibres and the intensity of the red colour (Listrat et al., 2016). Supplementation with a polyphenolic extract from Eucommia ulmoides leaves increased the $\mathrm{a}^{*}$ values and the abundance of MyHC I mRNA, whereas the abundance of MyHC IIb mRNA was decreased in comparison with the control group (Zhou et al., 2016). Thus, it can be speculated that the effective components of CHMs can enhance the expression and content of myoglobin in muscle. Alternatively, it may also enhance the animal antioxidant capacity by participating in some antioxidant enzymes synthesis, which effectively prevents the oxidation of myoglobin or oxygenated myoglobin to positive iron myoglobin. 
Yellowness $\left(\mathbf{b}^{*}\right)$. Some studies have found that CHMs (Eucommia ulmoides, coptis extract and milk thistle seeds) can reduce the yellowness of pork (Grela et al., 2020; Yi and Liu, 2020; Zhang et al., 2020). It was suggested that myoglobin content is a major factor decreasing the $b^{*}$ values, probably due to the higher concentration of red blood cells in the blood (Zhou et al., 2013).

On the other hand, in some studies it was suggested that CHMs have no effect on the $\mathrm{b}^{*}$ values (Astragalus membranaceus, Glycyrrhiza uralensis and Cinnamomum cassia; Wei et al., 2019) or even have a negative effect (Eucommia ulmoides; Long, 2015). In a study by Chelh et al. (2007), it was stated that the increase in the $b^{*}$ values may be due to the accumulation of fluorescent Schiff bases in lipid-protein complexes induced by oxidative stress. This may be due to the potential pro-oxidant activity of CHMs, which causes oxidation of lipids and proteins, leading to the accumulation of fluorescent Schiff bases. Furthermore, few studies have considered the $b^{*}$ values of pork fat, while yellow fat greatly influences consumer choices. Eucommia ulmoides leaves significantly increased the $b^{*}$ values in meat and back fat of pigs (Lee et al., 2009). Accordingly, this finding suggests that such herbs with negative effects should not be used, or their use must be reduced.

\section{Antioxidant capacity}

CHMs (Scutellaria baicalensis and Lonicera japonica extract; Radix Astragali, Radix Glycyrrhizae, Cortex Eucommiae) can effectively improve antioxidant capacity and reduce lipid oxidation (Liu et al., 2016; Yu et al., 2017). Oxidation is considered to be the main cause of the deterioration of meat products. Oxidation leads to the degradation of lipids and proteins, producing toxic compounds and discolouring meat. The most significant effect of dietary CHMs on pork quality may be its oxidative stability, while the literature almost agreed that the addition of CHMs (mulberry leaves, cinnamon extract, oleuropein extract, milk thistle seeds, Verbenaceae leaves extract, oregano essential oil) reduced the formation of malondialdehyde (MDA)/ thiobarbituric acidreactive substances (TBARS) during storage (Rossi et al., 2013; Cheng et al., 2017; Forte et al., 2017; Rossi et al., 2017; Fan et al., 2020; Grela et al., 2020; Luo et al., 2020; Rey et al., 2021). There is evidence that $5 \mathrm{mg} / \mathrm{kg}$ of Verbenaceae leaves extract increased vitamin $\mathrm{E}$ level and decreased lipid oxidation level in LDM (Rossi et al., 2013). It was also found that CHMs (mulberry leaves, extract from Eucommia ulmoides leaves, cinnamon extract and oregano essential oil (Cheng et al., 2017; Fan et al., 2020; Li et al., 2020; Luo et al., 2020)) supplementation could increase the activities of several antioxidant enzymes, including total antioxidant capacity, superoxide dismutase (SOD), glutathione peroxidase (GSH-Px) and catalase (CAT). Also, it was reported that herbs (fermented/ natural) significantly reduced MDA content in meat stored for 2 to 3 weeks, and increased GSH-Px activity (Ahmed et al., 2016). The study of CHMs on the expression of antioxidant related genes in pig muscle is rare. Only one study reported that dietary extract from Eucommia ulmoides leaves supplementation increased the expression of SOD1 mRNA in LTL of pigs, but there was no significant difference in the expression of GPXI and CAT (Li et al., 2020).

A high level of n-3 polyunsaturated fatty acids (PUFA) can increase the sensitivity of lipids to muscle peroxidation (Reis et al., 2011). A large amount of antioxidant enzymes may promote $n-3$ PUFA deposition in muscle by protecting lipid from oxidative damage. The antioxidant properties of CHMs are attributed to a variety of bioactive compounds. Flavonoids can reduce the occurrence of oxidation by increasing the expression of nuclear factor erythroid 2-related factor 2 (NRF2) and endogenous antioxidant enzymes (Singh et al., 2018).

However, most studies have only focused on lipid oxidation, and neglect protein oxidation. Only one study reported that supplementation of Eucommia ulmoides leaves extract in pig diets reduced the carbonyl content of LTL (Li et al., 2020). Additionally, most studies have only concentrated on the antioxidant effect of CHMs, ignoring their oxidative effect. Consequently, this requires us to pay attention to the oxidative effect and rational use of CHMs.

\section{Sensory quality}

Sensory quality is the whole consumer experience, including taste, juiciness, flavour, odour, tenderness and overall acceptance. In the previous studies, oregano essential oil, compound herbs (rosemary, garlic, oregano and ginger), garlic and essential oils (oregano, thyme, cinnamon and clove) had no significant effect on pork sensory quality (Janz et al., 2007; Simitzis et al., 2010; Panea and Ripoll, 2019). The average score of acceptance, tenderness, odour and taste on pork supplemented with herbal compounds (Valeriana officinalis and passionflower) were 5.60, 4.90, 5.91 and 5.75, respectively, and there was no significant difference in comparison with the control group. However, recent studies have found that CHMs can have also a positive effect on meat sensory scores. In cooked 
meat, the addition of Eucommia ulmoides leaves into animals' diet did not affect the odour, flavour and juiciness, but improved chewiness and overall acceptance (Lee et al., 2009). Oregano essential oil group achieved higher consistency scores, tenderness and overall acceptance in comparison with the control, but had no significant effect on juiciness and flavour grade (Cheng et al., 2017; Forte et al., 2017). Feeding milk thistle seeds to pigs improved pork springiness, and reduce hardness (32-40\%), gumminess (45-51\%) and chewiness (45-50\%) (Grela et al., 2020). Similarly, CHMs compounds (Cynonchum witfordii, Curcuma zedoaria, Pueraria thumbergiana) had higher sensory test scores in terms of colour, flavour, odour and overall acceptance (Grela et al., 2020). Verbenaceae leaves extract reduced the fat odour and rancid flavour intensity of cooked LDM (Rossi et al., 2013). The beneficial effect on the sensory quality of meat supplemented with CHMs may be attributed to the improvement of the oxidation stability promoted by the active substance from CHMs.

In the above-mentioned studies, most CHMs had no adverse effect on meat odour. As is widely known, it is very difficult to create a more favourable odour through feeding, even though it might be possible to create an unfavourable odour by changing the fat composition of the feed (Aaslyng and Meinert, 2017). In one study, all pigs sample had strong offodour, with scores from 4.33 to 9.33 , increasing with the increase of the garlic level (Holden et al., 1999). According to Leong et al. (2011), when garlic essential oil was added to the diet, the concentration of stink and indole in adipose tissue increased, and so the odour increased. However, the results of Panea and Ripoll (2019) showed that there was no difference in the taste score between the garlic and control groups. Thus, in practical applications, it is necessary to screen out the CHMs that produce a bad smell for pork and control their usage.

Only one study reported the effect of CHMs additives on the visual appraisal or purchase intention of pork. The visual appraisal scores of the control, garlic and compounds (oregano, thyme, cinnamon and clove) groups were 6.42, 6.02 and 5.73, respectively (Panea and Ripoll, 2019). The addition of CHMs reduced the visual appraisal scores but did not affect the purchase intention (Panea and Ripoll, 2019). The colour was defined as the most important factor influencing consumer perception, but Panea and Ripoll (2019) study did not measure meat colour. Therefore, further visual research should be carried out to meet the preferences of consumers.

All sensory traits deteriorate during refrigerated storage reducing shelf-life. Long shelf-life is essential in the processing, transportation and storage of meat products. However, only one study of CHMs reported this. According to Panea and Ripoll (2019), the pork from pigs fed diet with Verbenaceae extract showed a lower smell overall intensity compared with the fresh meat at day 12 and showed a difference in appearance and odour compared with the samples without added extract at day 15 .

\section{Meat quality overview}

According to the selected literature materials and results, the frequently used CHMs and their effects on meat quality were sorted out (Figure 1). The data reveals that these high-frequency used CHMs have favourable effects on improving pork IMF, enhancing WHC and reducing shear force, especially Astragalus membranaceus, Fructus Crataegi, Glycyrrhiza uralensis, Codonopsis pilosula, Pericarpium Citri Reticulatae, Eucommia

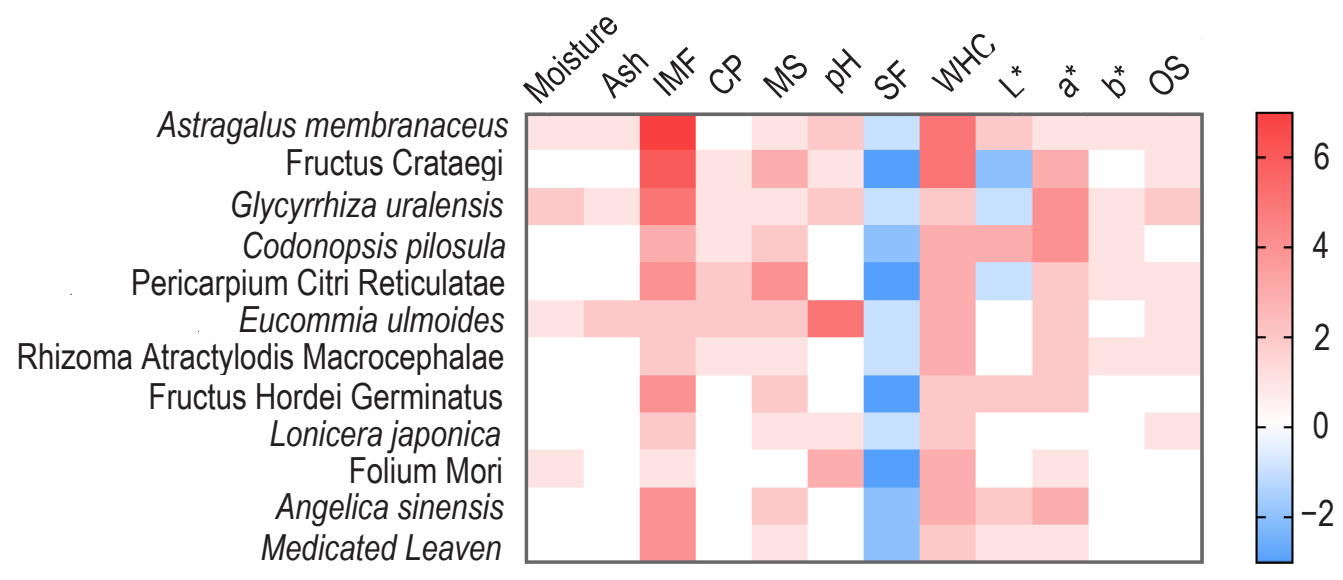

Figure 1. The effects of Chinese herbal medicines with high-frequency use on meat quality.

IMF - intramuscular fat, CP - crude protein, MS - marbling score, SF - shear force, WHC - water holding capacity, L* - lightness, $a^{*}$ - redness, $b^{*}$ - yellowness, OS - oxidation stability 
ulmoides, Rhizoma Atractylodis Macrocephalae. The CHMs mentioned above can improve the nutritional value of pork, as well as meat quality. Therefore, the CHMs in the image can be effectively used in the production of pork with improved quality.

The literature on the effect of CHMs on meat quality rarely discloses their chemical composition and bioactive compounds, only 11 publications disclose relevant information (Table 3), which may lead to misleading and affect the promotion and application of CHMs. In addition, it is necessary to pay attention to the dosage of CHMs in production. Except for mulberry leaves (3-15\%) and Silybum marianum seeds (3-6\%), the dosage currently used
The CHMs used in the above study include powder (directly crushed CHMs), essential oil and extract. Since the mechanism of different forms is various, it is necessary to study the effect of different forms of CHMs on meat quality. Moreover, the lack of detailed description of the preparation and standardization methods of CHMs extracts and essential oils results in the difficulty of repetition. The mechanism of CHMs active ingredients, nonactive ingredients and auxiliary matrix on pig meat quality is unfortunately not clear. Similarly, the interaction mechanism of compound CHMs additives is also still difficult to understand. Enzymes related to energy metabolism and glycolytic enzymes may

Table 3. Chemical composition and bioactive compounds of Chinese herbal medicines (CHMs)

\begin{tabular}{|c|c|c|c|}
\hline $\mathrm{CHMs}$ & Dosage, $\%$ & $\begin{array}{l}\text { Chemical composition (\% dry matter) or bioactive } \\
\text { compounds }\end{array}$ & References \\
\hline Mulberry leaves (dried, smashed) & $3-15$ & $\begin{array}{l}\text { CP 15.22-20.94, CF 11.44-31.59, ash 8.27-19.02, } \\
\text { NDF 25.35-25.41, ADF 19.09-19.25, calcium } \\
\text { 1.42-2.69, phosphorus } 0.16-0.26\end{array}$ & $\begin{array}{l}\text { He et al. (2019); Liu et al. (2019a); } \\
\text { Zeng et al. (2019); Fan et al. } \\
\text { (2020); Chen et al. (2021) }\end{array}$ \\
\hline Lonicera macranthoides (dried, smashed) & ) $0.5-1$ & $\begin{array}{l}\text { CP } 7.8 \text {, ash } 5.9 \text {, ADF } 32.7 \text {, NDF } 47.5 \text {, calcium } 0.75 \text {, } \\
\text { phosphorus } 0.14\end{array}$ & Long (2015) \\
\hline Silybum marianum seeds (dried, smashed) & 1) $3-6$ & $\begin{array}{l}\text { CP 22.1, CF 4.1, ash 0.32, ADF 27.01, NDF 33.47, } \\
\text { calcium } 0.48 \text {, phosphorus } 0.07\end{array}$ & Grela et al. (2020) \\
\hline $\begin{array}{l}\text { Punica granatum, Ginkgo biloba, } \\
\text { Glycyrrhiza uralensis (dried, smashed } \\
\text { or fermented) }\end{array}$ & 0.004 & $\begin{array}{l}\text { CP 10.98-12.08, EE 2.41-2.63, CF 9.83-11.90, } \\
\text { ash 2.62-19.39, calcium 0.12-0.13 }\end{array}$ & Ahmed et al. (2016) \\
\hline Extracted of cinnamon & $0.004-0.008$ & $99 \%$ cinnamaldehyde & Luo et al. (2020) \\
\hline Extract of Eucommia ulmoides leaves & $0.05-1$ & $82.8 \%$ chlorogenic acids & Li et al. (2020) \\
\hline Extract of Verbenaceae leaves & 0.001 & vitamin $\mathrm{E}$ and verbascoside & Rossi et al. (2017) \\
\hline
\end{tabular}

$\mathrm{CP}$ - crude protein, CF - crude fibre, NDF - neutral detergent fibre, ADF - acid detergent fibre, EE - ether extract

in research is generally less than $2 \%$, especially for the addition of extracts from $\mathrm{CHMs}$ and compound formulas $(<1 \%)$. As the medicinal resources, high dosage of CHMs may have negative effects on animal health.

\section{Conclusions}

Many Chinese herbal medicines (CHMs) formulations can improve pork intramuscular fat (IMF), $\mathrm{pH}$ value, tenderness, water holding capacity (WHC), redness and antioxidant capacity. However, it needs to be pointed out that a small number of CHMs can reduce the content of crude protein $(\mathrm{CP})$ in pork, and increase lightness and yellowness values, which has a negative impact on meat quality. There are also numerous CHMs that do not exert any significant effect on pork quality. This indicates that in order to benefit pig production, it is necessary to screen for the right formula and use CHMs properly. affect muscle properties and meat quality. However, there are few studies about CHMs in this area. As we all know, diet can affect the expression of genes connected with muscle metabolism and physiology. To summarize, the knowledge about the effect of CHMs on meat quality is still rare. Further studies on identifying individual bioactive components may help to analyse the molecular mechanism of CHMs. Furthermore, it is important to continue assessing the feasibility of CHMs in production and application under other conditions to improve pork production and quality.

\section{Acknowledgements}

This research was supported by the Agricultural competitive industry discipline team-building project of Guangdong Academy of Agricultural Sciences (202118TD), Guangdong Modern Agroindustry Technology Research System (2019KJ115, 
2020KJ115), Talent Project of the Guangdong Academy of Agricultural Sciences (R2017PYJG001), National Natural Science Foundation of China (31802103), Provincial Agricultural Science and Technology Innovation Promotion and Agricultural Resources and Ecological Environmental Protection Construction Project (2021KJ266), Guangzhou Municipal Science and Technology Project (201707020007), Guangdong Basic and Applied Basic Research Foundation, China (2020A1515010591).

\section{Conflict of interest}

The authors declare that there is no conflict of interest.

\section{References}

Aaslyng M.D., Meinert L., 2017. Meat flavour in pork and beef from animal to meal. Meat Sci. 132, 112-117, https://doi. org/10.1016/j.meatsci.2017.04.012

Ahmed S.T., Mun H.S., Islam M.M., Ko S.Y., Yang C.J., 2016. Effects of dietary natural and fermented herb combination on growth performance, carcass traits and meat quality in growerfinisher pigs. Meat Sci. 122, 7-15, https://doi.org/10.1016/j. meatsci.2016.07.016

Bi J., Zhang H., Lu J., Lei W., 2016. Nobiletin ameliorates isoflurane-induced cognitive impairment via antioxidant, anti-inflammatory and anti-apoptotic effects in aging rats. Mol. Med. Rep. 14, 5408-5414, https://doi.org/10.3892/ mmr.2016.5919

Chang J.J., Hsu M.J., Huang H.P., Chung D.J., Chang Y.C., Wang C.J., 2013. Mulberry anthocyanins inhibit oleic acid induced lipid accumulation by reduction of lipogenesis and promotion of hepatic lipid clearance. J. Agric. Food Chem. 61, 6069-6076, https://doi.org/10.1021/jf401171k

Chelh I., Gatellier P., Santé-Lhoutellier V., 2007. Characterisation of fluorescent Schiff bases formed during oxidation of pig myofibrils. Meat Sci. 76, 210-215, https://doi.org/10.1016/j. meatsci.2006.10.028

Chen D., Li W., Du M., Wu M., Cao B., 2015. Sequencing and characterization of divergent marbling levels in the beef cattle (Longissimus dorsi muscle) transcriptome. AsianAustralas. J. Anim. Sci. 28, 158-165, https://doi.org/10.5713/ ajas.14.0394

Chen J., Li W.C., Gu X.L., 2017. Optimized extraction, preliminary characterization, and in vitro antioxidant activity of polysaccharides from Glycyrrhiza uralensis Fisch. Med. Sci. Monit. 23, 1783-1791, https://doi.org/10.12659/ MSM.900471

Chen Y., Huang J., Hu J., Yan R., Ma X., 2019. Comparative study on the phytochemical profiles and cellular antioxidant activity of phenolics extracted from barley malts processed under different roasting temperatures. Food Funct. 10, 2176-2185, https: //doi.org/10.1039/C9FO00168A

Chen Y.J., Kim I.H., Cho J.H., Yoo J.S., Wang Q., Wang Y., Huang Y., 2008. Evaluation of dietary L-carnitine or garlic powder on growth performance, dry matter and nitrogen digestibilities, blood profiles and meat quality in finishing pigs. Anim. Feed Sci. Technol. 141, 141-152, https://doi.org/10.1016/j. anifeedsci.2007.05.025
Chen Z., Xie Y., Luo J., Chen T., Xi Q., Zhang Y., Sun J., 2021. Dietary supplementation with Moringa oleifera and mulberry leaf affects pork quality from finishing pigs. J. Anim. Physiol. Anim. Nutr. 105, 72-79, https://doi.org/10.1111/jpn.13450

Cheng C., Liu Z., Zhou Y., Wei H., Zhang X., Xia M., Deng Z., Zou Y., Jiang S., Peng J., 2017. Effect of oregano essential oil supplementation to a reduced-protein, amino acid-supplemented diet on meat quality, fatty acid composition, and oxidative stability of Longissimus thoracis muscle in growing-finishing pigs. Meat Sci. 133, 103-109, https://doi.org/10.1016/j.meatsci.2017.06.011

Cheng K., Yu C., Li Z., Li S., Yan E., Song Z., Zhang H., Zhang L., Wang T., 2020. Resveratrol improves meat quality, muscular antioxidant capacity, lipid metabolism and fiber type composition of intrauterine growth retarded pigs. Meat Sci. 170, 108237, https://doi.org/10.1016/j.meatsci.2020.108237

Corominas J., Ramayo-Caldas Y., Puig-Oliveras A., Estellé J., Castelló A., Alves E., Pena R.N., Ballester M., Folch J.M., 2013. Analysis of porcine adipose tissue transcriptome reveals differences in de novo fatty acid synthesis in pigs with divergent muscle fatty acid composition. BMC Genomics 14, 843, https:// doi.org/10.1186/1471-2164-14-843

Dang D.X., Kim Y.M., Kim I.H., 2020. Effects of a root extract from Achyranthes japonica Nakai on the growth performance, blood profile, fecal microbial community, fecal gas emission, and meat quality of finishing pigs. Livest. Sci. 239, 104160, https:// doi.org/10.1016/j.livsci.2020.104160

Dihal A.A., van der Woude H., Hendriksen P.J.M. et al., 2008. Transcriptome and proteome profiling of colon mucosa from quercetin fed F344 rats point to tumor preventive mechanisms, increased mitochondrial fatty acid degradation and decreased glycolysis. Proteomics 8, 45-61, https://doi.org/10.1002/ pmic.200700364

Fan L., Peng Y., Wu D., Hu J., Shi X.E., Yang G., Li X., 2020. Morus nigra L. leaves improve the meat quality in finishing pigs. J. Anim. Physiol. Anim. Nutr. 104, 1904-1911, https://doi.org/10.1111/ jpn.13439

Faustman C., Sun Q., Mancini R., Suman S.P., 2010. Myoglobin and lipid oxidation interactions: mechanistic bases and control. Meat Sci. 86, 86-94, https://doi.org/10.1016/j.meatsci.2010.04.025

Feng X., Lyu Y., Wu Z., Fang Y., Xu H., Zhao P., Xu Y., Feng H., 2014. Fructus ligustri lucidi ethanol extract improves bone mineral density and properties through modulating calcium absorptionrelated gene expression in kidney and duodenum of growing rats. Calcif. Tissue Int. 94, 433-441, https://doi.org/10.1007/ s00223-013-9825-4

Forte C., Ranucci D., Beghelli D., Branciari R., Acuti G., Todini L., Cavallucci C., Trabalza-Marinucci M., 2017. Dietary integration with oregano (Origanum vulgare L.) essential oil improves growth rate and oxidative status in outdoor-reared, but not indoor-reared, pigs. J. Anim. Physiol. Anim. Nutr. 101, e352-e361, https://doi.org/10.1111/jpn.12612

Gao Z., Zhang C., Tian W., Liu K., Hou R., Yue C., Wu Y., Wang D., Liu J., Hu Y., Yang Y., 2017. The antioxidative and hepatoprotective effects comparison of Chinese angelica polysaccharide (CAP) and selenizing CAP (SCAP) in $\mathrm{CCl}_{4}$ induced hepatic injury mice. Int. J. Biol. Macromol. 97, 46-54, https:// doi.org/10.1016/j.jijbiomac.2017.01.013

Gong A.G.W., Duan R., Wang H.Y., Kong X.P., Dong T.T.X., Tsim K.W.K., Chan K., 2018. Evaluation of the pharmaceutical properties and value of Astragali radix. Medicines 5, 46, https:// doi.org/10.3390/medicines5020046 
Grela E.R., Świątkiewicz M., Florek M., Wojtaszewska I., 2020. Impact of milk thistle (Silybum marianum L.) seeds in fattener diets on pig performance and carcass traits and fatty acid profile and cholesterol of meat, backfat and liver. Livest. Sci. 239, 104180, https://doi.org/10.1016/j.livsci.2020.104180

Hamedi S., Forouzanfar F., Rakhshandeh H., Arian A., 2019. Hypnotic effect of Portulaca oleracea L. on pentobarbital-induced sleep in mice. Curr. Drug Discov. Technol. 16, 198-203, https://doi.or $\mathrm{g} / 10.2174 / 1570163815666180308142543$

Hamill R.M., McBryan J., McGee C., Mullen A.M., Sweeney T., TalbotA., Cairns M.T., Davey G.C., 2012. Functional analysis of muscle gene expression profiles associated with tenderness and intramuscular fat content in pork. Meat Sci. 92, 440-450, https://doi. org/10.1016/j.meatsci.2012.05.007

Hao S., Xiao Y., Lin Y., Mo Z., Chen Y., Peng X., Xiang C., Li Y., Li W., 2016. Chlorogenic acid-enriched extract from Eucommia ulmoides leaves inhibits hepatic lipid accumulation through regulation of cholesterol metabolism in HepG2 cells. Pharm. Biol. 54, 251-259, https://doi.org/10.3109/13880209.2015.1029054

Harris E.S.J., Cao S., Littlefield B.A. et al., 2011. Heavy metal and pesticide content in commonly prescribed individual raw Chinese herbal medicines. Sci. Total Environ. 409, 4297-4305, https:// doi.org/10.1016/j.scitotenv.2011.07.032

He H., Lu Y.H., 2013. Comparison of inhibitory activities and mechanisms of five mulberry plant bioactive components against a-glucosidase. J. Agric. Food Chem. 61, 8110-8119, https:// doi.org/10.1021/jf4019323

He L.H., Chen G.S., Quan Q.X., Liu M.Z., Yang G., Yuan T.J., 2019. Effects of adding mulberry leaf powder in diets on the quality and amino acid content in muscle of pigs. J. Gansu Agric. Univ. 2019(1), 16-23, https://doi.org/10.13432/j.cnki. jgsau.2019.01.003

Hocquette J.F., Gondret F., Baéza E., Médale F., Jurie C., Pethick D.W., 2010. Intramuscular fat content in meat-producing animals: development, genetic and nutritional control, and identification of putative markers. Animal 4, 303-319, https://doi.org/10.1017/ S1751731109991091

Holden P.J., McKean J., Franzenburg E., 1999. Botanicals for pigs garlic. lowa State Univ. Anim. Indust. Rep. 1(1)

Hu G.Y., Cao X.Y., Cao R.L., Liu H.D., Duan Y.N., Wang B.H., 2018a. Effects of Chinese herbal medicine additives on fatty acid and cholesterol content in pork of different pig breeds. Swine Prod. 1, 65-68, https://doi.org/10.13257/j.cnki.21-1104/s.2018.01.025

Hu S., Dou X., Zhang L., Xie Y., Yang S., Yang M., 2018b. Rapid detection of aflatoxin $\mathrm{B} 1$ in medicinal materials of radix and rhizome by gold immunochromatographic assay. Toxicon 150, 144-150, https://doi.org/10.1016/j.toxicon.2018.05.015

Huang Y.C., Tsay H.J., Lu M.K., Lin C.H., Yeh C.W., Liu H.K., Shiao Y.J., 2017. Astragalus membranaceus-polysaccharides ameliorates obesity, hepatic steatosis, neuroinflammation and cognition impairment without affecting amyloid deposition in metabolically stressed APPswe/PS1dE9 mice. Int. J. Mol. Sci. 18, 2746, https://doi.org/10.3390/ijms18122746

Hughes J.M., Oiseth S.K., Purslow P.P., Warner R.D., 2014. A structural approach to understanding the interactions between colour, water-holding capacity and tenderness. Meat Sci. 98, 520-532, https://doi.org/10.1016/j.meatsci.2014.05.022

Isabel B., Cordero G., Olivares A., Daza A., Lopez-Bote C.J., 2014. Differential response of Iberian and lean pig crossbreeds to dietary linoleic acid administration. Span. J. Agric. Res. 12, 419-426, https://doi.org/10.5424/sjar/2014122-4361
Janz J.A.M., Morel P.C.H., Wilkinson B.H.P., Purchas R.W., 2007. Preliminary investigation of the effects of low-level dietary inclusion of fragrant essential oils and oleoresins on pig performance and pork quality. Meat Sci. 75, 350-355, https:// doi.org/10.1016/j.meatsci.2006.06.027

Kang S.N., Chu G.M., Song Y.M., Jin S.K., Hwang I.H., Kim I.S., 2012 The effects of replacement of antibiotics with by-products of oriental medicinal plants on growth performance and meat qualities in fattening pigs. Anim. Sci. J. 83, 245-251, https://doi. org/10.1111/j.1740-0929.2011.00942.x

Kim B.K., Hwang E.G., Jung D.J., Ha J.J., Oh D.Y., Choi C.B., 2014. Effects of kaolinite (macsumsuk) and herb mixtures on the quality and physicochemical properties of pork. Korean J. Food Sci. Anim. Resour. 34, 395-402, https://doi.org/10.5851/ kosfa.2014.34.3.395

Kong D., Li Y., Bai M., Deng Y., Liang G., Wu, H., 2017. A comparative study of the dynamic accumulation of polyphenol components and the changes in their antioxidant activities in diploid and tetraploid Lonicera japonica. Plant Physiol. Biochem. 112, 87-96, https://doi.org/10.1016/j.plaphy.2016.12.027

Kong X., Wu G., Yin Y., 2011. Roles of phytochemicals in amino acid nutrition. Front. Biosci. Scholar 13, 372-384, https://doi. org/10.2741/s 157

Kowalska G., 2020. Pesticide residues in some Polish herbs. Agriculture 10, 154, https://doi.org/10.3390/agriculture10050154

Lan R.X., Park J.W., Lee D.W., Kim I.H., 2017. Effects of Astragalus membranaceus, Codonopsis pilosula and allicin mixture on growth performance, nutrient digestibility, faecal microbial shedding, immune response and meat quality in finishing pigs. J. Anim. Physiol. Anim. Nutr. 101, 1122-1129, https://doi. org/10.1111/jpn.12625

Lee S.D., Kim H.Y., Song Y.M., Jung H.J., Ji S.Y., Jang H.D., Ryu J.W., Park J.C., Moon H.K., Kim I.C., 2009. The effect of Eucommia ulmoides leaf supplementation on the growth performance, blood and meat quality parameters in growing and finishing pigs. Anim. Sci. J. 80, 41-45, https://doi.org/10.1111/j.17400929.2008.00593.x

Lee Y.H., Kim Y.S., Song M., Lee M., Park J., Kim H., 2015. A herbal formula HT048, Citrus unshiu and Crataegus pinnatifida, prevents obesity by inhibiting adipogenesis and lipogenesis in 3T3-L1 preadipocytes and HFD-induced obese rats. Molecules 20, 9656-9670, https://doi.org/10.3390/molecules20069656

Leong J., Morel P.C.H., Purchas R.W., Wilkinson B.H.P., 2011. Effects of dietary components including garlic on concentrations of skatole and indole in subcutaneous fat of female pigs. Meat Sci. 88, 45-50, https://doi.org/10.1016/j.meatsci.2010.12.001

Li H., Zhao J., Deng W., Li K., Liu H., 2020. Effects of chlorogenic acid-enriched extract from Eucommia ulmoides Oliver leaf on growth performance and quality and oxidative status of meat in finishing pigs fed diets containing fresh or oxidized corn oil. J. Anim. Physiol. Anim. Nutr. 104, 1116-1125, https://doi. org/10.1111/jpn.13267

Li R., Hu G.L., Liu M., Hou G.F., Peng W., Long S.Y., Huang X.G., 2014. Effects of adding Chinese herbal medicine in diet on growth performance, carcass traits and meat quality of fattening pigs. Chin. Anim. Husb. Vet. Med. 2014(2), 96-100, https://kns.cnki. net $/$ cms/detail/detail.aspx?dbcode=CJFD\&filename=GWXK2 01402024\&dbname=CJFD2014

Lim D.W., Lee Y., Kim Y.T., 2014. Preventive effects of Citrus unshiu peel extracts on bone and lipid metabolism in OVX rats. Molecules 19, 783-794, https://doi.org/10.3390/molecules19010783

Lin F.H., Luo P.J., Liang M.D., Xie X.Y., Ouyang H.X., Li G.H., Wu X.J., 2017. Analysis of Chinese medicinal herbs for poisonous properties. J. Huizhou Univ. 2017(3), 56-60, https://doi. org/10.16778/j.cnki.1671-5934.2017.03.010 
Lin Z., Ye L., Li Z., Huang X., Lu Z., Yang Y., Xing H., Bai J., Ying Z., 2020. Chinese herb feed additives improved the growth performance, meat quality, and nutrient digestibility parameters of pigs. Anim. Models Exp. Med. 3, 47-54, https://doi.org/10.1002/ ame2.12104

Listrat A., Lebret B., Louveau I., Astruc T., Bonnet M., Lefaucheur L., Picard B., Bugeon J., 2016. How muscle structure and composition influence meat and flesh quality. Sci. World J. 2016, 3182746, https://doi.org/10.1155/2016/3182746

Liu W., Lv X., Huang W., Yao W., Gao X., 2018. Characterization and hypoglycemic effect of a neutral polysaccharide extracted from the residue of Codonopsis Pilosula. Carbohydr. Polym. 197, 215-226, https://doi.org/10.1016/j.carbpol.2018.05.067

Liu W.C., Pi S.H., Kim I.H., 2016. Effects of Scutellaria baicalensis and Lonicera japonica extract mixture supplementation on growth performance, nutrient digestibility, blood profiles and meat quality in finishing pigs. Ital. J. Anim. Sci. 15, 446-452, https:// doi.org/10.1080/1828051X.2016.1202736

Liu Y., Li Y., Peng Y., He J., Xiao D., Chen C., Li F., Huang R., Yin Y., 2019a. Dietary mulberry leaf powder affects growth performance, carcass traits and meat quality in finishing pigs. J. Anim. Physiol. Anim. Nutr. 103, 1934-1945, https://doi. org/10.1111/jpn.13203

Liu Y., Wang W., Sun M., Ma B., Pang L., Du Y., Dong X., Yin X., Ni J., 2019b. Polygonum multiflorum-induced liver injury: clinical characteristics, risk factors, material basis, action mechanism and current challenges. Front. Pharmacol. 10, 1467, https://doi.org/10.3389/fphar.2019.01467

Long C.M., 2015. Effects of cane leaves of lonicera (Lonicera macranthoides) and chlorogenic acid on meat quality of fattening pigs. MSc Thesis. Hunan Agricultural University. Hunan (China), https://kns.cnki.net/kcms/detail/detail.aspx?dbcode $=$ CMFD\&dbname $=$ CMFD201702\&filename $=1017039762$.nh \&v=meZCxfku59\%25mmd2Ba9EH4prtNLpam3KJTsdlh\%25 mmd2FHrFZmGO2cEhOQguG1B0lqw6lvhwsA\%25mmd2Be

Luo Q., Li N., Zheng Z., Chen L., Mu S., Chen L., Liu Z., Yan J., Sun C., 2020. Dietary cinnamaldehyde supplementation improves the growth performance, oxidative stability, immune function, and meat quality in finishing pigs. Livest. Sci. 240, 104221, https://doi.org/10.1016/j.livsci.2020.104221

Madak-Erdogan Z., Gong P., Zhao Y.C. et al., 2016. Dietary licorice root supplementation reduces diet-induced weight gain, lipid deposition, and hepatic steatosis in ovariectomized mice without stimulating reproductive tissues and mammary gland. Mol. Nutr. Food Res. 60, 369-380, https://doi.org/10.1002/ mnfr.201500445

Nan G., Meng X., Song N., Liu Z., Liu Y., Li Y., Yang G., Zheng S., 2021. Uptake and distribution characteristic and health risk assessment of heavy metal(loid)s in Platycodon Grandiflorum (Jacq.) A.DC. with growth from a medicinal herb garden of Xi'an, China. Biol. Trace Elem. Res. 199, 2770-2778, https:// doi.org/10.1007/s12011-020-02364-9

Ozyigit I.I., Yalcin B., Turan S., Saracoglu I.A., Karadeniz S., Yalcin I.E., Demir G., 2018. Investigation of heavy metal level and mineral nutrient status in widely used medicinal plants' leaves in Turkey: Insights into health implications. Biol. Trace Elem. Res. 182, 387-406, https://doi.org/10.1007/s12011-017-1070-7

Panea B., Ripoll G., 2019. Plant-derived extracts feed-addition and packaging type influence consumer sensory perception of pork. Nutrients 11, 2652, https://doi.org/10.3390/nu11112652

Reis R.J.S., Xu L., Lee H. et al., 2011. Modulation of lipid biosynthesis contributes to stress resistance and longevity of $C$. elegans mutants. Aging 3, 125-147, https://doi.org/10.18632/aging. 100275
Rey A.I., De Cara A., Segura J.F., Martí P., Hechavarría T., Calvo L., 2021. Dietary oleuropein extract supplementation and its combination with a-tocopheryl acetate and selenium modifies the free fatty acid profile of pork and improves its stability. J. Sci. Food Agric. 101, 2337-2344, https://doi.org/10.1002/ jsfa.10855

Rincón-Cervera M.Á., Valenzuela R., Hernandez-Rodas M.C., Barrera C., Espinosa A., Marambio M., Valenzuela A., 2016. Vegetable oils rich in alpha linolenic acid increment hepatic n-3 LCPUFA, modulating the fatty acid metabolism and antioxidant response in rats. Prostaglandins Leukot. Essent. Fatty Acids 111, 25-35, https://doi.org/10.1016/j. plefa.2016.02.002

Rodrigues E.L., Marcelino G., Silva G.T., Figueiredo P.S., Garcez W.S., Corsino J., Guimarães R.C.A., Freitas K.C., 2019. Nutraceutical and medicinal potential of the Morus species in metabolic dysfunctions. Int. J. Mol. Sci. 20, 301, https://doi.org/10.3390/ ijms20020301

Rossi R., Pastorelli G., Cannata S., Tavaniello S., Maiorano G., Corino C., 2013. Effect of long term dietary supplementation with plant extract on carcass characteristics meat quality and oxidative stability in pork. Meat Sci. 95, 542-548, https://doi. org/10.1016/j.meatsci.2013.05.037

Rossi R., Ratti S., Pastorelli G., Crotti A., Corino C., 2014. The effect of dietary vitamin $\mathrm{E}$ and verbascoside on meat quality and oxidative stability of Longissimus Dorsi muscle in mediumheavy pigs. Food Res. Int. 65, Part A, 88-94, https://doi. org/10.1016/j.foodres.2014.03.062

Rossi R., Stella S., Ratti S., Maghin F., Tirloni E., Corino C., 2017. Effects of antioxidant mixtures in the diet of finishing pigs on the oxidative status and shelf life of longissimus dorsi muscle packaged under modified atmosphere. J. Anim. Sci. 95, 4986-4997, https://doi.org/10.2527/jas2017.1603

Shan C.-H., Guo J., Sun X. et al., 2018. Effects of fermented Chinese herbal medicines on milk performance and immune function in late-lactation cows under heat stress conditions. J. Anim. Sci. 96, 4444-4457, https://doi.org/10.1093/jas/sky270

Shao F., Gu L., Chen H., Liu R., Huang H., Ren G., 2016. Comparation of hypolipidemic and antioxidant effects of aqueous and ethanol extracts of Crataegus pinnatifida fruit in high-fat emulsioninduced hyperlipidemia rats. Pharmacogn. Mag. 12, 64-69, https://doi.org/10.4103/0973-1296.176049

Shen X.L., Li A.P., Yao M., Xia X.L., 2021. Influence of compound Chinese herbal medicine additive on meat quality of growing finishing pigs. Acta Ecol. Anim. Domastic 42, 37-42, https:// kns.cnki.net/kcms/detail/detail.aspx?dbcode=CJFD\&dbname $=$ CJFDLAST2021\&filename $=J C S T 202102007 \& v=1 \mathrm{rH} 70 \mathrm{e} \%$ 25mmd2FXUVSiGsHu\%25mmd2FmStPN4yrFCFmQJP30R K6jJ26yvRC2j1BCoHuta1b6nOYyML

Shuang J., Deli G., Ma Q., Bayin M., Niu X., 2001. Influence of licorice root extract by-product on pigs' fattening and content of muscular free amino acids in compound additive. J. Inner Mongolia Agric. Univ. 22, 75-79, https://doi.org/10.3969/j. issn.1009-3575.2001.02.017

Simitzis P.E., Symeon G.K., Charismiadou M.A., Bizelis J.A., Deligeorgis S.G., 2010. The effects of dietary oregano oil supplementation on pig meat characteristics. Meat Sci. 84, 670-676, https://doi.org/10.1016/j.meatsci.2009.11.001

Singh A., Zhao K., 2017. Treatment of insomnia with traditional Chinese herbal medicine. Int. Rev. Neurobiol. 135, 97-115, https://doi.org/10.1016/bs.irn.2017.02.006

Singh S., Dubey V., Meena A., Siddiqui L., Maurya A.K., Luqman S., 2018. Rutin restricts hydrogen peroxide-induced alterations by up-regulating the redox-system: An in vitro, in vivo and in silico study. Eur. J. Pharmacol. 835, 115-125, https://doi. org/10.1016/j.ejphar.2018.07.055 
Song C., Xu Y., Lu Y., 2020. Use of Tripterygium wilfordii Hook F for immune-mediated inflammatory diseases: progress and future prospects. J. Zhejiang Univ. Sci. B 21, 280-290, https:// doi.org/10.1631/jzus.B1900607

Tian S.H., Cao H.Z., Xu Q., Fan M., Lu C.L., 2009. Effects of compound Chinese herbal medicine additives on production performance and meat quality of finishing pigs. Heilongjiang Anim. Sci. Vet. Med. 2009(14), 68-69, https://kns.cnki.net/ $\mathrm{kcms} /$ detail/detail.aspx?dbcode=CJFD\&filename=HLJX2009 14046\&dbname $=$ CJFD2009

Ting A., Chow Y., Tan W., 2013. Microbial and heavy metal contamination in commonly consumed traditional Chinese herbal medicines. J. Tradit. Chin. Med. 33, 119-124, https://doi. org/10.1016/S0254-6272(13)60112-0

Toldrá F., Flores M., Aristoy M., 1995. Enzyme generation of free amino acids and its nutritional significance in processed pork meats. Dev. Food Sci. 37, 1303-1322, https://doi. org/10.1016/S0167-4501(06)80235-9

Tong Q., 2016. Effects of tea dust and Chinese herbal medicine on the growth of pigs, meat and diarrhea properties. MSc Thesis. Hunan Agricultural University. Hunan (China), https:// kns.cnki.net/kcms/detail/detail.aspx?dbcode=CMFD\&dbn ame $=$ CMFD201702\&filename $=1017039454 . n h \& v=w n Y-$ $8 \mathrm{KMtn} \% 25 \mathrm{mmd} 2 \mathrm{FGQXxh0mbLr4710Y1tQ7mcJOPrRM9uN}$ 2\%25mmd2FQt9A309hPJel5JzIVLDluhW

Tsuduki T., Kikuchi I., Kimura T., Nakagawa K., Miyazawa T., 2013. Intake of mulberry 1-deoxynojirimycin prevents diet-induced obesity through increases in adiponectin in mice. Food Chem. 139, 16-23, https://doi.org/10.1016/j.foodchem.2013.02.025

Wang H.J., Jiang H., Zhou T.Z., Zhen Z.G., 2013. Effects of Chinese herbal compound additives on the quality of poached pork. Chin. Feed 22, 26-28, https://doi.org/10.15906/j.cnki.cn112975/s.2013.22.010

Wang L., Sun J., Yi Q., Wang X., Ju X., 2012a. Protective effect of polyphenols extract of adlay (Coix lachryma-jobi L. var. mayuen Stapf) on hypercholesterolemia-induced oxidative stress in rats. Molecules 17, 8886-8897, https://doi.org/10.3390/ molecules 17088886

Wang S., Hu Y., Tan W., Wu X., Chen R., Cao J., Chen M., Wang Y., 2012b. Compatibility art of traditional Chinese medicine: From the perspective of herb pairs. J. Ethnopharmacol. 143, 412-423, https://doi.org/10.1016/j.jep.2012.07.033

Wang Y., Xie Q., Sun S., Huang B., Zhang Y., Xu Y., Zhang S., Xiang H., 2018b. Probiotics-fermented Massa Medicata Fermentata ameliorates weaning stress in piglets related to improving intestinal homeostasis. Appl. Microbiol. Biotechnol. 102, 10713-10727, https://doi.org/10.1007/ s00253-018-9438-y

Wang Z., Wang H., Wang H., Li Q., Li Y., 2019. Heavy metal pollution and potential health risks of commercially available Chinese herbal medicines. Sci. Total Environ. 653, 748-757, https:// doi.org/10.1016/j.scitotenv.2018.10.388

Wang Z.Y., Duan Y.H., Li F.N., Yang B.C., Zhang J.X., Hou S.Z., 2017. Dietary supplementation with Lonicera macranthoides leaf powder enhances growth performance and muscle growth of Chinese Tibetan pigs. Livest. Sci. 206, 1-8, https://doi. org/10.1016/j.livsci.2017.09.026

Wang Z.Y., Li J.Q., Dong X., Duan L., 2018a. Effects of adding Chinese herbal medicine into a diet on growth performance, meat quality and muscle fiber characteristics of fattening pigs. Chin. Feed 4, 55-59, https://doi.org/10.15906/j.cnki. cn11-2975/s.20180411

Warriss P.D., 1982. The relationship between $\mathrm{pH}_{45}$ and drip in pig muscle. Int. J. Food Sci. Technol. 17, 573-578, https://doi. org/10.1111/j.1365-2621.1982.tb00216.x
Warshafsky S., Kamer R.S., Sivak S.L., 1993. Effect of garlic on total serum cholesterol. Ann. Intern. Med. 119, 599-605, https:// doi.org/10.7326/0003-4819-119-7_part_1-19931001000009

Waszkiewicz-Robak B., Szterk A., Rogalski M., Rambuszek M., Kruk M., Rokowska E., 2015. Nutritional value of raw pork depending on the fat type contents in pigs feed. Acta Sci. Pol. Technol. Aliment. 14, 153-163, https://doi.org/10.17306/J. AFS.17

Wei X.L., Yang B.L., Feng X.Y., Huang Y.R., Liu F.F., Lou Y.X., Xiao C.M., Yao T., Cao L., 2019. The effect of natural plant feed on the growth performance, blood characteristics and meat quality of finishing pigs. Chin. Feed 2019(15), 72-75, https://doi.org/10.15906/j.cnki.cn11-2975/s.20191517

Wen L., Guo X., Liu R.H., You L., Abbasi A.M., Fu X., 2015. Phenolic contents and cellular antioxidant activity of Chinese hawthorn "Crataegus pinnatifida". Food Chem. 186, 54-62, https://doi. org/10.1016/j.foodchem.2015.03.017

Włoch A., Kapusta I., Bielecki K., Oszmiański J., Kleszczyńska H., 2013. Activity of hawthorn leaf and bark extracts in relation to biological membrane. J. Membr. Biol. 246, 545-556, https:// doi.org/10.1007/s00232-013-9566-3

Wood J.D., Lambe N.R., Walling G.A., Whitney H., Jagger S., Fullarton P.J., Bayntun J., Hallett K., Bünger L., 2013. Effects of low protein diets on pigs with a lean genotype. 1. Carcass composition measured by dissection and muscle fatty acid composition. Meat Sci. 95, 123-128, https://doi. org/10.1016/j.meatsci.2013.03.001

Wood J.D., Richardson R.I., Nute G.R., Fisher A.V., Campo M.M., Kasapidou E., Sheard P.R., Enser M., 2004. Effects of fatty acids on meat quality: a review. Meat Sci. 66, 21-32, https:/ doi.org/10.1016/S0309-1740(03)00022-6

Wu J., Chen H., Li H., Tang Y., Yang L., Cao S., Qin D., 2016. Antidepressant potential of chlorogenic acid-enriched extract from Eucommia ulmoides Oliver bark with neuron protection and promotion of serotonin release through enhancing Synapsin I expression. Molecules 21, 260, https://doi. org/10.3390/molecules21030260

Wu T., Yu Z., Tang Q., Song H., Gao Z., Chen W., Zheng X., 2013. Honeysuckle anthocyanin supplementation prevents diet-induced obesity in C57BL/6 mice. Food Funct. 4, 1654-1661, https://doi.org/10.1039/c3fo60251f

Wu X., Wang S., Lu J., Jing Y., Li M., Cao J., Bian B., Hu C., 2018. Seeing the unseen of Chinese herbal medicine processing (Paozhi): advances in new perspectives. Chin. Med. 13, 4, https://doi.org/10.1186/s13020-018-0163-3

Xu J., Hou H., Hu J., Liu B., 2018. Optimized microwave extraction, characterization and antioxidant capacity of biological polysaccharides from Eucommia ulmoides Oliver leaf. Sci. Rep. 8, 6561, https://doi.org/10.1038/s41598-018-24957-0

Xu J.K., Kurihara H., Zhao L., Yao X.S., 2007. Theacrine, a special purine alkaloid with sedative and hypnotic properties from Cammelia assamica var. kucha in mice. J. Asian Nat. Prod. Res. 9, 665-672, https://doi. org/10.1080/10286020601103155

Xu W., Guan R., Shi F., Du A., Hu S., 2017. Structural analysis and immunomodulatory effect of polysaccharide from Atractylodis macrocephalae Koidz. on bovine lymphocytes. Carbohydr. Polym. 174, 1213-1223, https://doi.org/10.1016/j. carbpol.2017.07.041

Xu X.B., Hu R., Qu Y.Q., 2012. Effect of Chinese herb feed additives on fattening performance and meat quality of swine Jiangsu J. Agric. Sci. 28, 571-574, https://doi.org/10.3969/j. issn.1000-4440.2012.03.022 
Yan L., Meng Q.W., Ao X., Zhou T.X., Yoo J.S., Kim H.J., Kim I.H., 2011. Effects of fermented garlic powder supplementation on growth performance, blood characteristics and meat quality in finishing pigs fed low-nutrient-density diets. Livest. Sci. 137, 255-259, https://doi.org/10.1016/j.livsci.2010.09.024

Yang D., Bian L.Q., Liu X.J., Chen J., 2015. Effects of Chinese herbal medicine additives on the production performance and meat quality of fattening pigs. Feed Res. 2015(7), 1-5, https://doi. org/10.13557/j.cnki.issn1002-2813.2015.07.001

Yi Y., Liu Y.M., 2020. Effects of coptis extract on growth performance, nutrient digestibility and meat quality of finishing pigs. Chin. Feed 2020(8), 29-32, https://doi.org/10.15906/j.cnki.cn112975/s.20200808

Yu Q.P., Feng D.Y., Xia, M.H. et al., 2017. Effects of a traditional Chinese medicine formula supplementation on growth performance, carcass characteristics, meat quality and fatty acid profiles of finishing pigs. Livest. Sci. 202, 135-142, https:// doi.org/10.1016/j.livsci.2017.05.029

Zeng S.H., 2016. Effects of Chinese herbal on the growth performance, meat quality and flavor in finishing pigs. MSc Thesis. South China Agricultural University. Guangzhou (China), https://kns.cnki.net/kcms/detail/detail.aspx?dbcod $\mathrm{e}=$ CMFD\&dbname $=$ CMFD201701\&filename $=1016922706$. nh\&v=VTJQ6CFcbzBagQjw7NE4zBIQIIUNtKL8VTS5UsQe GTQgAOhW4BIWjZZQ5Ej5vhmK

Zeng Z., Jiang J., Yu J., Mao X., Yu B., Chen D., 2019. Effect of dietary supplementation with mulberry (Morus alba L.) leaves on the growth performance, meat quality and antioxidative capacity of finishing pigs. J. Integr. Agric. 18, 143-151, https://doi. org/10.1016/S2095-3119(18)62072-6
Zhang C., Luo J., Yu B., Zheng P., Huang Z., Mao X., He J., Yu J., Chen J., Chen D., 2015. Dietary resveratrol supplementation improves meat quality of finishing pigs through changing muscle fiber characteristics and antioxidative status. Meat Sci. 102, 15-21, https://doi.org/10.1016/j.meatsci.2014.11.014

Zhang Q., Li N., Liu Q.Y., Zhang Q., Jia L.J., Zhang S.M., 2020. Effects of Eucommia ulmoides powder in diets on growth performance, carcass traits, meat quality traits and economic benefits of Songliao black pig. Feed Ind. 2020(23), 34-38, https://doi.org/10.13302/j.cnki.fi.2020.23.007

Zhou T.X., Zhang Z.F., Kim I.H., 2013. Effects of dietary coptis Chinensis herb extract on growth performance, nutrient digestibility, blood characteristics and meat quality in growingfinishing pigs. Asian-Australas. J. Anim. Sci. 26, 108-115, https://doi.org/10.5713/ajas.2011.11400

Zhou Y., Ruan Z., Li X.L., Mi S.M., Jiang M., Liu W.H., Yang H.S., Wu X., Jiang G.L., Yin Y.L., 2016. Eucommia ulmoides Oliver leaf polyphenol supplementation improves meat quality and regulates myofiber type in finishing pigs. J. Anim. Sci. 94, 164-168, https://doi.org/10.2527/jas.2015-9551

Zong X., Yan X., Wu J., Liu Z., Zhou H., Li N., Liu L., 2019. Potentially cardiotoxic diterpenoid alkaloids from the roots of Aconitum carmichaelii. J. Nat. Prod. 82, 980-989, https://doi. org/10.1021/acs.jnatprod.8b01039 